\title{
Credit Risk Analysis on Euro Government Bonds-Term Structures of Default Probabilities
}

\author{
Takeaki Kariya • Yoshiro Yamamura • \\ Yoko Tanokura · Zhu Wang
}

Published online: 20 February 2015

(C) The Author(s) 2015. This article is published with open access at Springerlink.com

\begin{abstract}
In this paper, we make a comprehensive credit risk analysis on government bonds (GBs) of Germany, France, Italy, Spain and Greece over the period 2007.42012.3, where interest rate (IR) differential, GB price differential, default probability (DP) and credit default swap (CDS) are considered. First, applying the GBpricing model in Kariya (Quantitative methods for portfolio analysis: MTV approach. Springer, Berlin, 1993) to these GB prices, we derive the term structures of interest rates (TSIRs) and discuss on the Maastricht convergence condition for the IR-differentials among these states relative to the German TSIRs and make some observations on some divergent tendencies. The results are associated with the business cycles and budgetary condition of each state. In the second part, to substantiate this viewpoint, we first make credit risk price spread analysis on price differentials and derive the term structures of default probabilities (TSDPs) of the French, Italian, Spanish and Greek GBs relative to the German GBs, where the corporate bond (CB) model proposed in Kariya (Advances in modern statistical theory and applications: a Festschrift for Professor Morris L. Eaton. Institute of Mathematical Statistics, Beachwood, 2013) is used in the derivation. Then it is empirically shown that the TSDPs show a significant divergent movement at the end of 2011, affected by the Euro Crisis. In addition, the TSDPs of
\end{abstract}

\footnotetext{
T. Kariya $(\varangle) \cdot$ Y. Yamamura

GSGB, Meiji University, Tokyo, Japan

e-mail: kariya@meiji.ac.jp; thekariya70@gmail.com

Y. Yamamura

e-mail: yyama@meiji.ac.jp

Y. Tanokura

GSAMS, Meiji University, Tokyo, Japan

e-mail: tanokura@meiji.ac.jp

Z. Wang

ZW System, University of South Carolina, Columbia, SC, USA
} 
these GBs are empirically shown to be almost linear functions of the differences of the TSIRs, which enables us to state the Maastricht condition in terms of DP. Thirdly the effectiveness of our TSDPs is empirically verified by comparing them with the corresponding CDSs against US dollars.

Keywords European Economic and Monetary Union - Maastricht treaty .

Government bond pricing model - Credit risk price spread - Term structures of interest rates and default probability $\cdot$ Credit default swap

\section{Introduction}

The Financial Crisis in 2008-2009 and the European Crisis thereafter made many European states (countries) in the the European Economic and Monetary Union (EEMU) confronting severe budgetary and unemployment problems, as reflected in Greek economy. As of May 2013, there are 27 countries in the European Union (EU) among which 17 states form the EEMU. The European problem has been affecting global economies through trade relations and financial markets, and naturally the world concerns about their future movements, because a collapse of the EEMU would make a significantly serious impact on the world economy. As a matter of fact, the 2012 GDPs of Germany, France, Italy and Spain in the EEMU are respectively ranked the 4th, 5th, 9th, and 13th in the world and the total GDP of these four states is greater than the GDP of China, implying the global importance of these countries in view of the world trade system and financial system.

Though the currency has been integrated in the EEMU, the sovereignties of making finance for fiscal policy by issuing government bond (GB) have not yet been integrated in the system. Since these GBs are of common currency unit "euro", the bonds issued by the EEMU states are substitutable from investors' viewpoint and the price differentials observed in the GB markets basically show the substitutable rates or equivalently credit risks in euros, which is made by alert and sensitive investors. Hence the GB prices of the same attributes (coupon and maturity) in the EEMU states will naturally exhibit or reflect credit quality in their price differentials, where we only treat GBs with fixed coupons. In other words, the price differentials with bond attributes adjusted will directly exhibit market evaluations of the DPs (default probabilities) projected by forward-looking investors. Here it is noted that the investors who form prices in the market will have certain views and perspectives on risks of possible defaults of the GB issuers over some time horizons, given the past information on microeconomic and macroeconomic movements, business cycles, and government budgetary conditions, etc.

In this paper, via interest rate differential (IR-differential), price differential ( $\mathrm{P}$ differential), default probability (DP) and credit default swap(CDS), we will make a comprehensive credit risk analysis on the GB price data of the Five States; Germany, France, Italy, Spain and Greece over 2007.4-2012.3. The names of the Five States are often respectively represented by the symbols D, F, I, S, and Gr below. For example, their GBs are abbreviated as DGB, FGB, IGB, SGB and GrGB respectively. The analysis includes the derivations and comparisons of the term structure of interest 
rates (TSIR) implied by those GB prices, and it is associated with credit risk analysis on FGB, IGB, SGB and GrGB relative to DGB, where the price differentials are analyzed and the term structures of default probabilities (TSDPs) are derived and compared. In our terminology the credit risk of the $k$ th state (issuer) at current time $t$ is the TSDP $\left\{p_{t}^{k}(s) \equiv P\left(\tau_{t}^{k} \leq s\right): 0<s \leq s_{M}^{k}\right\}$ that the $k$ th government (state) cannot timely pay the coupons nor fully redeems the principals of its issued GBs at future time $t+s$, where $k=\mathrm{F}, \mathrm{I}, \mathrm{S}, \mathrm{Gr}$ and $\tau_{t}^{k}$ is the default time random variable of the $k$ th state. Our future time horizon for analysis is commonly fixed as the 10-year term $(0,10]$ from $t$. Throughout this paper the time $t$ of analysis is dropped from our notation and the TSDP is simply denoted by $\left\{p^{k}(s)\right\}$. By its definition the TSDP curve of $p^{k}(s)$ is increasing and unconditional at each time and we will estimate $p^{k}(s)$ with monthly cross-sectional data of the GB prices for each state $k$.

It is noted that in interest rate analysis and credit risk analysis, its data source naturally makes a great impact on the effectiveness of modeling and analysis. In particular when it is aimed to derive a DP (default probability) from a set of data, we distinguish the two approaches: (1) Backward-looking approach and (2) Forward-looking approach. In Backward-looking approach microeconomic and macroeconomic time series data over a past period is used for modeling and analysis and the data on defaulted firms and non-defaulted firms in the past is associated with economic, business and financial data. But these data are often generated under different environments with possibly different economic regimes. Typically, statistical or econometric models which use time series data on defaults and non-defaults belong to this approach. Examples are intensity model, survival model, classification model, rating transition model, logit-probit model, etc. In Forward-looking approach, current (cross-sectional) market data such as GB or CB (corporate bond) prices, interest rates, swap rates, stock prices, credit default swap (CDS) etc. is used to look forward over a future term with concept of DP for those firms that have not defaulted. These current market prices are supposed to reflect and include investors' views, projection and perspectives on future economic and financial movements or budgetary conditions of firms or states over a future term, given past time series information. A typical example is that a current cross-sectional set of GB prices of different maturities will give a TSIR over a future term, which is nothing but investors' views at current time on future interest rates.

We remark on liquidity risk. In our view liquidity will be inseparable from credit quality. In fact, liquidity risk is tightly related with credit risk and generally speaking, when economy is not in financial crisis, the lower the credit quality is, the less the liquidity is, which is in fact implied by the fact that the lower the credit quality is, the smaller the size of investors' funds is in the market (see, e.g., Friewald et al. 2012). Also the volume of the issued GBs standing in the market (depth of the market) matters in view of liquidity because the larger it is, the more easily the investors sell or buy bonds without market impact.

In our analysis, to derive TSIRs, the forward-looking GB-pricing model proposed in Kariya (1993) and applied in Kariya et al. (2012) (shortened KWWDY 2012) is applied to each monthly cross-sectional set of GB prices. And to derive TSDPs relatively to DGB, the forward-looking $\mathrm{CB}$ (Corporate Bond) pricing model proposed in Kariya (2013) is also applied to each monthly cross-sectional set of FGB, IGB, 
$\mathrm{SGB}$, and GrGB, which are regarded as CBs in the model, while DGBs are viewed as non-defaultable reference GBs.

In derivations of TSIRs, P-differentials and TSDPs, we use each monthly crosssectional set of GB price data, where price data is observed at the last business day of each month and the period of analysis is 2007.4-2012.3. Our arguments are sometimes made associated with the conditions in the Maastricht Treaty, which we will discuss in Sect. 2 and show a legitimacy of regarding DGB as a reference GB.

In Sect. 3, first our cross-sectional GB pricing model is reviewed, and then the TSIRs of the Five States are derived cross-sectionally in each month over the period 2007.42012.3. The model contains the heteroscedasticity and correlation structure of prices in the stochastic discount function, which naturally introduces a bond duration structure. Then from a viewpoint of the Maastricht convergence problem on the IR-differentials in Sect. 2 we associate time series paths of their TSIRs with business cycles of the Five States (German, France, Italy, Spain and Greece), where the business cycles are measured by the ESI (Economic Sentiment Indicator). Note that the IR-differential itself is a measure of credit risk and the relationships between our TSIRs and TSDPs are considered in Sect. 6.

In Sect. 4, we look into the P-differentials of GBs relative to DGB because they provide direct credit risk measures on FGB, IGB, SGB and GrGB in terms of euros. In fact, we propose the credit risk price spread (CRiPS) as a market credit risk measure that evaluates the credit P-differentials in euros of each GB of the Four States (France, Italy, Spain and Greece) relative to the corresponding DGB-equivalent bond of the same maturity and the same coupon rate, where the prices are adjusted for the bond attributes of maturity and coupon. It in fact measures a default likelihood of each individual bond in euro, which is similar to the default distance measure that uses current stock price, and it can be used in risk management of GB portfolios. And we make some empirical observations concerning the cross-sectional and time series differences of the CRiPSs of the Four States along business cycles together with the budgetary conditions of each state and historical events.

In Sect. 5 with monthly GB price data of the Five States for the period 2007. 4-2012.3, the TSDPs of the Four States are estimated via our CB pricing model, where the mean discount function derived from the DGB pricing model is used for discounting future defaultable CFs of GBs in the Four States. Here the recovery rates are assumed to be 0 because it is difficult to set specific nonzero rates for comparison. The time series movements of the TSDPs of the Four States are compared in view of business cycles, their budgetary problems and events revealed by the Greek Shocks in 2009.11, the Euro Crisis in 2010.4 and Financial Crisis in 2008.9-2009.3. The 10-year DPs of Italy and Spain are shown to be dramatically increasing over $30 \%$ in the Euro Crisis.

In Sect. 6 the Maastricht condition on the IR-differentials are considered in terms of DPs. The DPs are regressed on the IR-differentials in time series and shown to have an almost perfect linear relationship with the IR-differentials. The result is not surprising because it is in fact due to a structural relation between our GB-pricing model and CB-pricing model, and so it can be used as a conversion formula from IR-differentials to DPs and vice versa. 
In Sect. 7 to show the effectiveness of our DP measure and analysis in this paper, for each state we associate each DP $p_{k}(s)$ up to term $s$ with the CDS (credit default swap) of the same maturity $s$. Here a CDS is a credit derivative which pays its holder the GB principal 100 euros in US dollars when the issuer gets defaulted. In our analysis we regress CDS prices (premiums) on the levels of DPs and slopes of TSDPs, the best model is selected for each maturity $s$ and show that CDS prices are well explained by our TSDPs.

In the literature there are many theoretical and empirical researches on credit risk. But to our knowledge, there seems no such paper as this paper treating credit risk unconditionally in view of forward-looking modeling. Most theoretical researches in the area of mathematical finance take a time-continuous setting in view of noarbitrage concept. The books by Duffie and Singleton (2003) and Lando (2004) are well known. A common feature of these time-continuous theories is that all the stochastic processes are Markovian including processes of interest rate and credit risk intensity. Unfortunately speaking from a viewpoint of empirical analysis, actual interest rates and credit processes will not be Markovian since business cycles are not.

In his book, Duffie (2011) comprehensively describes his default intensity approach to corporate credit risk modeling together with time series empirical analysis, where most results are based on his previous papers such as Duffie et al. (2007, 2009), which consider frailty correlated defaults. The model is a doubly stochastic Poisson intensity model, which is extended as predictive intensity model in Duan et al. (2011).

On the other hand, a traditional approach to bond pricing will be represented by the econometric approach in Nelson and Siegel (1987), among others. They assume a specific form of non-stochastic term structure of interest rates including level, steepness, curvature and scale parameters. There are many papers associated with this model and its estimation and forecast procedure (e.g., Diebold and Li 2006). In credit risk analysis the yield curve approach often uses yield spreads between YTMs (yield-to-maturity) or par-yields derived for GBs and CBs. On the other hand, we take a price approach to measuring TSIRs, CRIPSs and TSDPs through GB price model, where TSIR and TSDP are approximated by polynomials.

\section{The Maastricht Treaty and Our Problem}

The Maastricht Treaty, which was signed in February 1992 and entered into force on 1 November 1993, describes the concept and vision of the EEMU and outlines the 5 convergence criteria for EU member states to comply with in order to enter the EEMU (see, e.g., Maastricht Treaty, Wikipedia, Treaty of Maastricht on European Union). As is well known, the EEMU was established with 27 countries in 2002 and was awarded the 2012 Nobel Peace Prize. In the treaty the Maastricht convergence criteria (or simply convergence criteria) are stipulated in order to achieve financial stability within the eurozone, and the economic conditions for an EU member to join the EEMU are required to meet:

1. Its inflation rate shall be less than the average of the 3 lowest rates plus $2 \%$.

2. Its annual government budget deficit over GDP shall be less than $3 \%$.

3. Its government debt-to-GDP ratio shall be less than $60 \%$. 


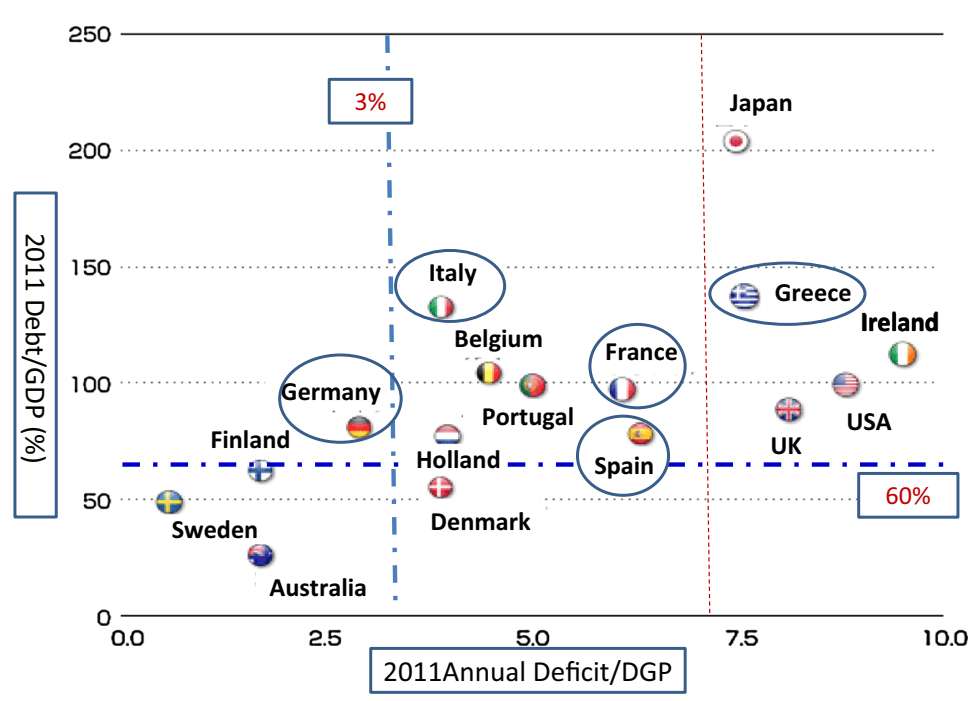

Data:OECD Economic Outlook (2011), graphed by Reuters and modified by the authors

Fig. 1 The budgetary conditions of some European countries, USA and Japan in 2011

4. Its exchange rates in the past year shall be stable.

5. Its long-term (10 year) interest yield average in the past year of a state that seeks currency integration shall be no more than $2.0 \%$ higher than the unweighted arithmetic average of the similar 10-year government bond yields in the $3 \mathrm{EU}$ member states with the lowest inflation.

After the financial crisis in 2008-2009, some of the EEMU members themselves are unable to satisfy the criteria (2) and (3) among others, which makes credit quality of government bonds (GBs) differentiated through their price differentials because they are issued under the same currency unit, which in turn makes the IR and hence the credit risk (default probability) of those states differentiated. In other words, even in the EEMU the convergence is questioned under the current situation. The problem of IR differentials in (5) is of course closely related to the conditions (2) and (3) on the budget deficit differentials in percentage. Our analysis based on GB prices is greatly related to the condition (5).

The budget problem is described in Fig. 1, where the vertical axis and the horizontal axis respectively represent the debt-to-GDP ratio and the annual government budget deficit over GDP in 2011. It shows that though the budgetary condition of Japan is exceptionally bad, the debt-to-GDP ratios of the Five States are all larger than $60 \%$ in 2011 against (3) and the annual government budget deficit over GDP is larger than $3 \%$ against (2) except for Germany. In these two measures Germany is the best state among the five and hence we take DGB as our reference state for comparisons in interest analysis and credit analysis though the budgetary condition does not fully explain credit risk.

It is interesting to point out that the debt-to-GDP ratio of Spain is smaller than that of France, though Spanish budgetary condition became worse rapidly in 2012. 


\section{Interest Rate Differentials and Convergence Criterion}

In this section we apply the GB pricing model in KWWDY (2012) to DGBs, FGBs, GrGBs, IGBs, and SGBs to derive their TSIRs and compare them to discuss on some differences of the TSIRs in association with business cycles. In Sect. 6 the results will be used to convert IR-differentials into DPs and the Maastricht convergence condition will be stated in DPs.

To describe the model, let the $k \mathrm{~GB}(g)$ denote the $g$ th bond of the $k$ th state at time $t$ for analysis, where $k=\mathrm{D}, \mathrm{F}, \mathrm{I}, \mathrm{S}, \mathrm{Gr}$, and $g=1, \ldots, G_{t}^{k}$. Let $P_{g t}^{k}$ denote the $k \mathrm{~GB}(g)$ price at $t$, where $G^{k}$ is the sample size of the $k \mathrm{~GB}$ prices at $t$. In the sequel, time $t$ is fixed and the suffix is omitted from each variable. Let $s_{g 1}^{k}<s_{g 2}^{k}<\cdots<s_{g M^{k}(g)}^{k}$ denote the future times measured in years from $t$ at which the CFs of the $k \mathrm{~GB}(g)$ are generated, and $s_{g M^{k}(g)}^{k}$ is the maturity of the $k \mathrm{~GB}(g)$. Then the GB pricing model is given by

$$
P_{g}^{k}=\sum_{j=1}^{M^{k}(g)} C_{g}^{k}\left(s_{g j}^{k}\right) D_{g}^{k}\left(s_{g j}^{k}\right) \quad\left(g=1, \ldots, G^{k}\right)
$$

In (3.1), $D_{g}^{k}(s)$ is a stochastic discount function which possibly depends on bond attributes, and the realization (at $t$ ) of each price $P_{g}^{k}$ is regarded as equivalent to the realization (at $t$ ) of the whole discount function $\left\{D_{g}^{k}(s): 0 \leq s \leq s_{g M^{k}(g)}^{k}\right\}$. Here $C_{g}^{k}\left(s_{g j}^{k}\right)^{\prime} s\left(j=1,2, \ldots, M^{k}(g)-1\right)$ are the coupons and $C_{g}^{k}\left(s_{g M^{k}(g)}^{k}\right)$ is the coupon plus the principal 100 (Euro) of the $k \mathrm{~GB}(g)$. For example, in the case of the IGB, coupons are paid semi-annually and so with $k=\mathrm{I}$

$$
C_{g}^{k}\left(s_{g j}^{k}\right)=0.5 c^{k} \text { for } j=1,2, \ldots, M^{k}(g)-1 \text { and } C_{g}^{k}\left(s_{g M^{k}(g)}^{k}\right)=0.5 c^{k}+100 \text {. }
$$

But in the case of the other GBs, coupons are paid annually.

The stochastic discount function is assumed to be decomposed into the attributeindependent mean discount function $\bar{D}^{k}(s)$ and the attribute-dependent stochastic part $\Delta_{g}^{k}(s)$

$$
D_{g}^{k}(s)=\bar{D}^{k}(s)+\Delta_{g}^{k}(s) .
$$

While in KWWDY (2012) $\bar{D}^{k}(s)$ is also assumed to be attribute-dependent to look into the pricing behaviors of bond investors, here it is assumed to be attribute-independent to compare GB market prices in different states. Inserting (3.2) into the model in (3.1) yields

$$
P_{g}^{k}=\sum_{j=1}^{M^{k}(g)} C_{g}^{k}\left(s_{g j}^{k}\right) \bar{D}^{k}\left(s_{g j}^{k}\right)+\eta_{g}^{k} \text { with } \eta_{g}^{k}=\sum_{j=1}^{M^{k}(g)} C_{g}^{k}\left(s_{g j}^{k}\right) \Delta_{g}^{k}\left(s_{g j}^{k}\right)
$$


We approximate the mean discount function $\bar{D}^{k}(s)$ by a polynomial of the $p$ th order;

$$
\bar{D}^{k}(s)=1+\delta_{1}^{k} s+\delta_{2}^{k} s^{2}+\cdots+\delta_{p}^{k} s^{p}
$$

since any continuous function on a closed interval can be uniformly approximated by a polynomial.

On the other hand, the specification of the stochastic part of $D_{g}^{k}(s)$ is made by

$$
\operatorname{Cov}\left(D_{g}^{k}\left(s_{g j}^{k}\right), D_{h}^{k}\left(s_{h m}^{k}\right)\right)=\operatorname{Cov}\left(\Delta_{g}^{k}\left(s_{g j}^{k}\right), \Delta_{h}^{k}\left(s_{h m}^{k}\right)\right)=\left(\sigma^{k}\right)^{2} \lambda_{g h}^{k}
$$

for all $j$ and $m$, where

$$
\lambda_{g h}^{k}=\left\{\begin{array}{ll}
1 & (g=h) \\
\rho^{k} e_{g h}^{k} & (g \neq h)
\end{array} \text { with } e_{g h}^{k}=\exp \left(-\xi^{k}\left|s_{g M^{k}(g)}^{k}-s_{h M^{k}(h)}^{k}\right|\right) .\right.
$$

This specification implies that

(1) the longer the maturity of each bond is, the larger the variance of each price is, and

(2) the larger the difference of maturities of two bonds, the smaller the covariance is. It is noted that the covariance in (3.5) is independent of the individual CF time points of two bonds except for the maturities. In this speculation the covariance of $P_{g}^{k}$ and $P_{h}^{k}$ becomes

$$
\operatorname{Cov}\left(P_{g}^{k}, P_{h}^{k}\right)=\left(\sigma^{k}\right)^{2} \lambda_{g h}^{k} \varphi_{g h}^{k} \text { with } \varphi_{g h}^{k}=\sum_{j=1}^{M^{k}(g)} \sum_{m=1}^{M^{k}(h)} C_{g}^{k}\left(s_{g j}^{k}\right) C_{h}^{k}\left(s_{h m}^{k}\right)
$$

Now our GB-pricing model for state $k$ is reduced to a regression model;

$$
\begin{aligned}
& y^{k}=X^{k} \beta^{k}+\eta^{k} \text { with } \beta^{k}=\left(\delta_{1}^{k}, \delta_{2}^{k}, \ldots, \delta_{p}^{k}\right)^{\prime}: p \times 1, \\
& y^{k}=\left(y_{1}^{k}, y_{2}^{k}, \ldots, y_{G^{k}}^{k}\right)^{\prime}: G^{k} \times 1, y_{g}^{k}=P_{g}^{k}-a_{g}^{k}, a_{g}^{k}=\sum_{j=1}^{M^{k}(g)} C_{g}^{k}\left(s_{g j}^{k}\right),
\end{aligned}
$$

and the covariance matrix;

$\operatorname{Cov}\left(\eta^{k}\right)=\left(\operatorname{Cov}\left(\eta_{g}^{k}, \eta_{h}^{k}\right)\right)=\left(\operatorname{Cov}\left(P_{g}^{k}, P_{h}^{k}\right)\right)=\left(\sigma^{k}\right)^{2}\left(\lambda_{g h}^{k} \varphi_{g h}^{k}\right) \equiv\left(\sigma^{k}\right)^{2} \Phi\left(\rho^{k}, \xi^{k}\right)$

This specification naturally introduces not only a heteroscedasticity and correlation structure into the model but also a bond duration effect into the variances and covariances of the prices. The parameter $\beta^{k}$ in the mean discount function $\bar{D}^{k}(s)$ are estimated via the GLS (generalized least squares) method, which minimizes the objective function 


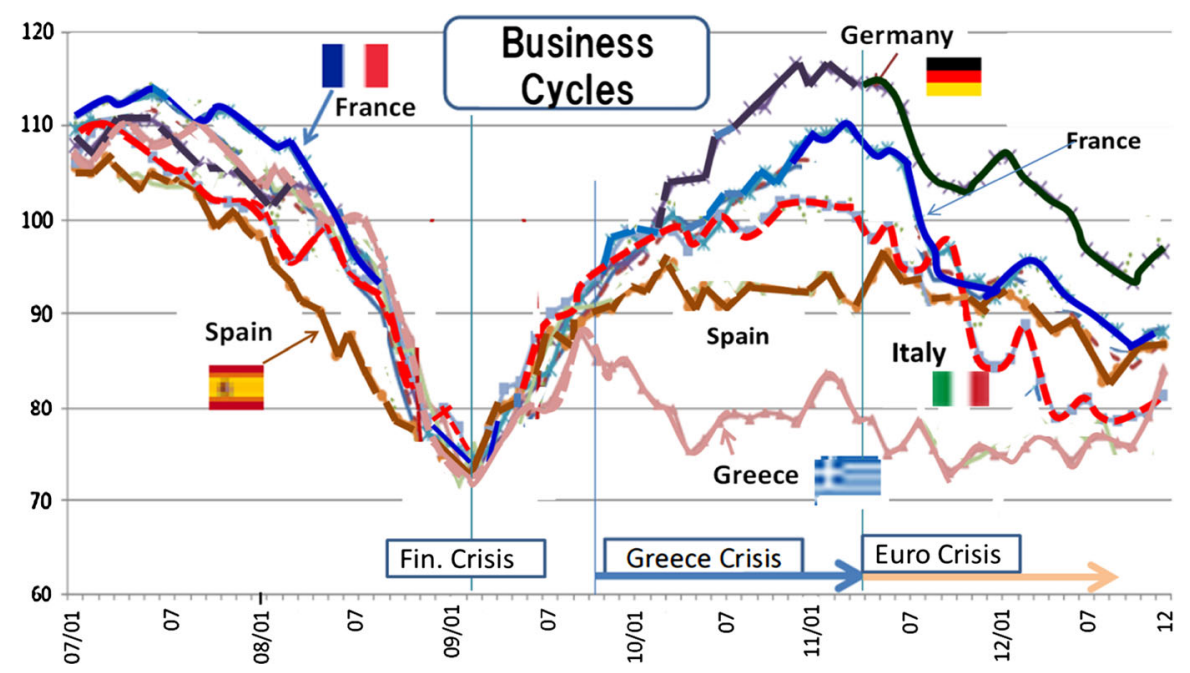

Fig. 2 Business Cycles of European economies. Data source: ESI (Economic Sentiment Indicator) of Economic and Financial Affairs, European Commission

$$
\psi\left(\beta^{k}, \rho^{k}, \xi^{k}\right)=\left[y^{k}-X^{k} \beta^{k}\right]^{\prime}\left[\Phi\left(\rho^{k}, \xi^{k}\right)\right]^{-1}\left[y^{k}-X^{k} \beta^{k}\right]
$$

with respect to the unknown parameters (see Kariya and Kurata 2004 for the effectiveness of GLS).

Once $\bar{D}^{k}(s)$ is estimated, the TSIR of the $k \mathrm{~GB}$ at time $t$ is estimated by

$$
r^{k}(s)=-\left[\log \bar{D}^{k}(s)\right] / s \text { with } 0<s \leq 10 .
$$

Before we apply the model to data, we look into the business cycles of the Five States and a brief history of events. In Fig. 2 the ESIs (Economic Sentiment Indicators) of EEMU states, published by the European Commission, are graphed, where the ESI is based on economic surveys and summarized as diffusion index, and the average of ESIs over 1990-2011 is set equal to 100 .

Though the ESI represents the economic sentiments of industries in private sector, it describes the business cycles of each state, which affect the levels of IRs (at time $t$ ) and even the budgetary condition of each government. The graph was originally made by JETRO and modified by the authors. The average of ESIs over 1990-2011 is set equal to 100 .

From Fig. 2 it is observed:

(1) The ESIs of the Fives hit a peak around 2007.6 almost simultaneously though the Spanish ESI was the lowest among the Fives from the peak through the downward slope up to 2009.1.

(2) From the peak to the points in 2008.7 the ESIs gradually decreased and then in the financial crisis period of 2008.8-2009.3 they dramatically dropped down about $30 \%$ to the bottom (trough) in 2009.3. The bottom was common to all the ESIs. 

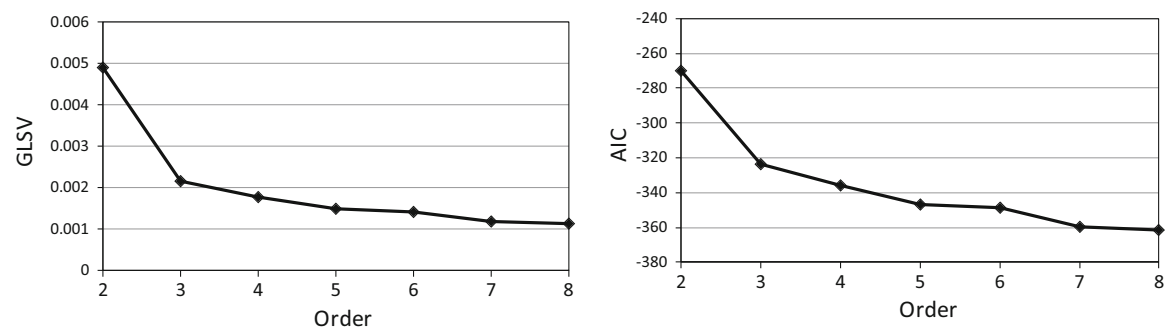

Fig. 3 The average AICs and the average minimized GLSVs defined by $(\widehat{\psi} / G)^{1 / 2}$ are plotted for the case of DGB over the period 2005.9-2010.8

(3) Then the ESIs of the Fives moved upward simultaneously up to the points in 2009.10, one month before the announcement of a huge budget deficit by Greece Government (Greek Crisis) in 2009.11.

(4) Since then, the ESIs separated each other and those of Italy, Spain and Greece did not go up much relative to those of Germany and France. From 2009.12 concerns about the budgetary conditions of Italy and Spain in addition to Greece spread globally and the credit rating agencies downgraded the GBs of Greece in 2009.12.

(5) In 2010.4 Greece requested the IMF and the EU Government a bailout and in 2010.5 the IMF and the EU Government created an emergent bailout system.

(6) In 2011, the ESIs of the Fives hit another peak around 2011.3 and then went down. Along this downward movement the IGBs and SGBs were sold off and their yields (interest rates) went up significantly, as will be shown later.

(7) Except those of Germany and France, the ESIs of Italy, Spain and Greece never reached the level in 2007.6 around 2011.3.

Now we apply the model to each monthly data set of cross-sectional GB prices from 2007.4 through 2012.3 (5 years). In Table 2 the sample size of each monthly data set is given for each state over the period. The sample sizes of DGB vary from 35 to 42 and tend to increase on the average. On the other hand, the average sample size of FGB is about 37 for the period up to 2010.3 but thereafter it is reduced to about 25. In other words, the French Government did not issue many GBs after 2010.3. In the case of SGB the sample size tends to increase almost monotonically from 16 through 24, while in the case of IGB they tend to increase from 28 to 42 over time. However, Greece issued less GBs and it tends to increase from 16 to 23 up to 2010.5 and thereafter tends to decrease to 16 except for the case of 2012.3 with sample size 2. In 2012.3 it seems that Greece could not issue new bonds after the Greek Crisis.

In selecting a model in (3.4), we need to specify the order $p$ of the polynomial. Figure 3 shows the AIC values and the averages of the 60 minimized values $\left(\widehat{\psi}_{/}^{k} G^{k}\right)^{1 / 2}$ 's of the objective function in (3.8) when $p$ changes. Of course, as $p$ increases, the average decreases since the parameter increases. In the case of DGB and IGB there are a moderate sample size for each set of data and hence we might be able to take $p=8$. However considering the other cases with smaller samples and taking into account the fact that $p=6$ in the cases of USGB and JGB (Japanese GB) (see KWWDY 2012), we take $p=6$ below, which is common to all the models of the Fives. 


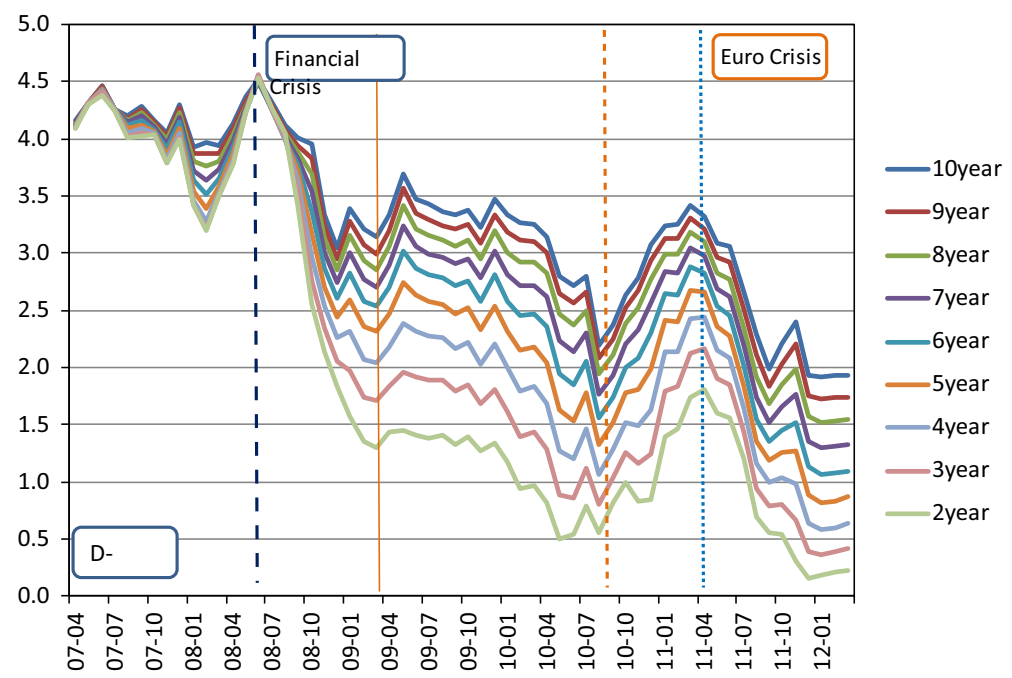

Fig. 4 Term Structures of Interest Rates (TSIRs) implied by DGB prices

In Fig. 4, we plot the TSIRs of DGBs, denoted by D-TSIRs, which is estimated through (3.11).

Some observations follow:

(1) From 2007.4 to 2008.6, the German economy was good enough to keep the 10 year IR about $4.5 \%$ and the differences of short term and long term IRs were small, implying that the economy was close to the peak. It hit the peak with almost flat $\operatorname{TSIR} r^{D}(1) \approx r^{D}(2) \approx \cdots \approx r^{D}(10)=0.05$ in 2008.06.

(2) From 2008.7 to 2009.3 , the interest rates dropped down rapidly and significantly along the subprime shock up and its aftermath, and the TSIRs became upward where the longer the terms are, the larger the rates. The Statistical Bureau of the European Commission identified 2009.3 as the bottom of the business cycles of European economy as in Fig. 1. The $r^{D}(10)$ rates dropped from $4.6 \%$ in 2008.6 to 3.28 in 2009.3 and further to $2.25 \%$ in 2010.8 , which corresponds to the business cycles of Germany in Fig. 1.

(3) At the bottom of the business cycles in 2009.3 the D-IRs did not drop much though the gaps between shorter rates and longer rates were widened and the upward slope of the TSIR became steep.

(4) After 2009.3 on, the German ESI moved up till 2011.3 in which the business cycles hit another peak, though the Greek budgetary crisis appeared in 2009.11. However, $r^{D}$ (10) stayed at levels of more than $3 \%$ after 2009.3 till 2010.3, and then suddenly dropped down to $2.4 \%$ in 2010.8 , which is not consistent with the movement of the German ESI.

(5) The period of 2010.4 through 2010.8 was reported to be the period in which Germany had to make some financial contribution to keep the EEMU system for Greece and other states. 

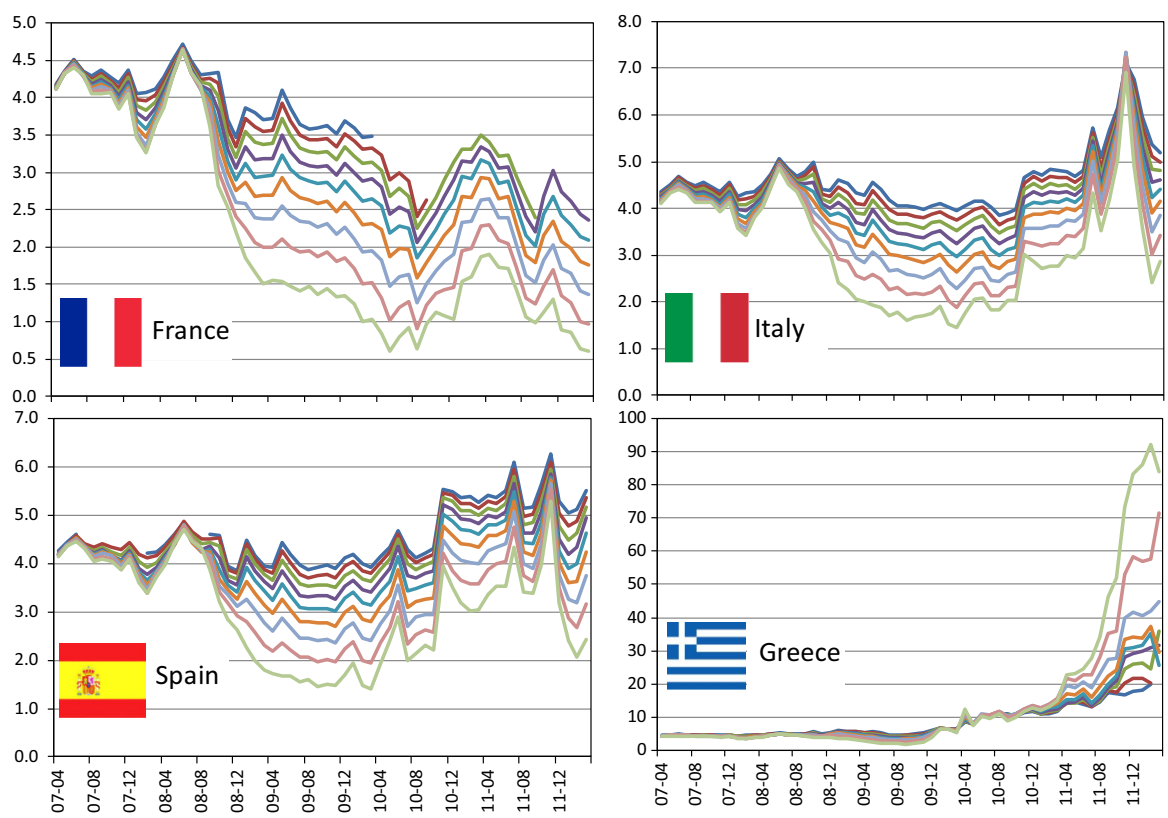

Fig. 5 TSIRs of France, Italy, Spain and Greece

(6) After that, the $r^{D}$ (10) moved up to the level of $3.4 \%$ in 2011.3, where 2011.3 corresponds to the peak month of the ESI. Thereafter $r^{D}(10)$ went down along the downward movement of the ESI.

In Fig. 5 the TSIRs of the Four States (France, Italy, Spain and Greece) are plotted. It is first noted that the scales of each vertical axis in these graphs are different. The reason why the graphs of French $r^{F}(10)$ and $r^{F}(9)$ are cut off in between the period is that no FGBs of 10 year and 9 year maturities beyond the cut-off points are available in our data set, where no extrapolation is made in estimating IRs.

It is observed from Fig. 5 that French TSIRs move more like German TSIRs over all and that the TSIRs of Italy, Spain and Greece move in completely different manner, though up to 2007.7 all the IRs including the German rates are almost same. In fact, they moved up significantly after the Greek Shock in 2010.4, implying that some potential budgetary or credit problems in the latter states are revealed. The 10-year IRs of these three states remain at more than $4 \%$ level for almost all the months even when the business cycles are around the trough in 2009.3, while the 10-year German IR dropped to $2.4 \%$ in 2010.8. This implies that the credit risk of the three states gets larger than that of Germany. In fact, it is often the case that credit risk is analyzed through the IR-differentials $r^{k}(j)-r^{D}(j)$ 's between $k-$ IR and D-IR of common maturity jyears, where $k=\mathrm{F}, \mathrm{I}, \mathrm{S}, \mathrm{Gr}$ and $k-\mathrm{IR}$ stands for the interest rate of the $k$ th state at each time $t$. In Sect. 6 the IR-differentials are analyzed in association with DPs.

As in Fig. 5, the Greek TSIRs are divergent. In particular, from the starting point 2010.4 in Euro crisis they go over $10 \%$ and reach $20 \%$ in 2011.4. Then at high 


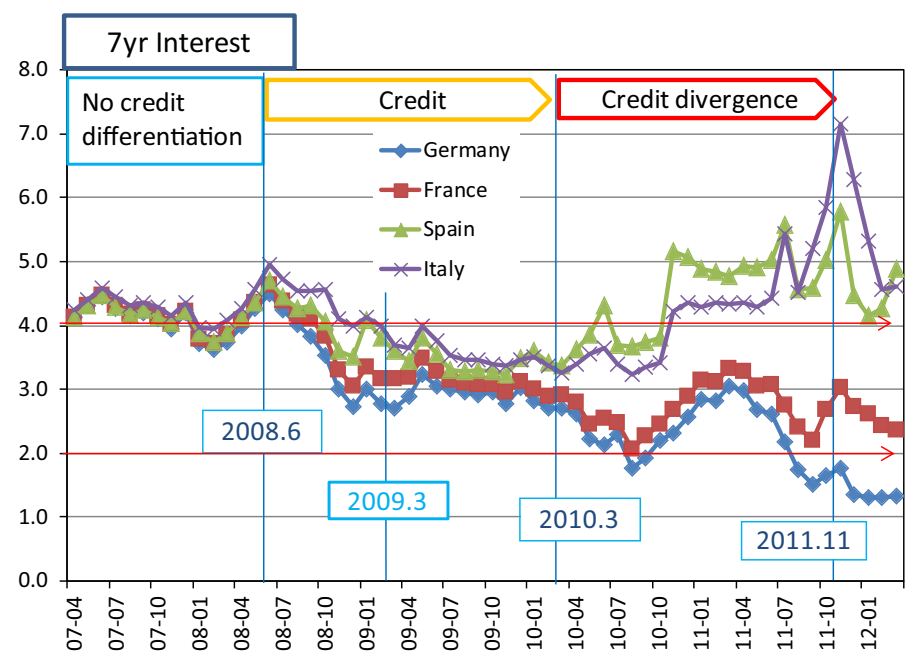

Fig. 6 The 7-year interest rate movements of Germany, France, Italy and Spain for 2007.4-2012.3

space they increase and in 2011.10 the 10 year IR reaches $50 \%$, implying a state of bankruptcy in GrGB. In fact, as will be shown in Fig. 9, the 10 year DP of GrGB is more than $60 \%$ in 2011.10 . For this reason, we sometimes omit the case of GrGB from our analysis in the sequel.

The D-IRs, F-IRs, I-IRs and S-IRs of 7-year maturity are drawn for the Five States over the period 2007.4-2012.3 in Fig. 6. From Fig. 6 it is easily observed that I-IRs and S-IRs gradually get separated from D-IRs and F-IRs. The period is divided into 4 sub-periods;

(a) 2007.4-2008.6, (b) 2008.7-2010.3,

(c) 2010.4-2011.11, (d) 2011.12-2012.3.

We respectively call them (a) sub-period of no differentiation, (b) sub-period of differentiation, (c) sub-period of divergence and (d) sub-period of stabilization.

In the period (a) the 4 IRs stick together without credit differentiation, representing a unification of the EEMU. This was also shown in the ESIs in Fig. 2 when their economies were good. The sub-period (b) includes the period of the subprime financial crisis and there the I-IRs and S-IRs start to separate themselves from the D-IRs and F-IRs, though the gaps are less than $2 \%$, as is required in the Maastricht condition (5) for participation in the EEMU.

However, in the period (c) after Greece requested a bailout to the IMF and the ECB (European Central Bank), investors concerned about the budgetary situations of Italy and Spain governments and sold IGBs and SGBs relative to DGBs and FGBs. In that period, the budget problems in fact turned out to be serious and, as is shown in Fig. 1, the annual deficit/GDP ratios of France, Italy and Spain go over $3 \%$, where that ratio of Greece is $7.3 \%$. In addition, the debt/GDP ratio of Italy at the end of 2011 is about $135 \%$ and close to that of Greece, while the debt/GDP ratio of Spain is about $75 \%$ and a bit less than that of Germany. The unemployment rates of these states get worse in this period. In (d), after the ECB, German Government and the IMF responded to 
the bailout request, the IR differentials get smaller though the gaps between Italy and Germany and between Spain and Germany are far larger than $2 \%$. It is noted that the F-IRs almost stick to the D-IRs until 2011.10 but thereafter the gaps widened.

No doubt, the credit risk of Italy and Spain gets worse especially in the sub-period (c) and it may be measured as IR-differential. In Sect. 5 we will make correspondence between the IR-differential and DP as our measure of credit risk after we derive TSDPs of the Four States in Sect. 4. In addition, the CDS prices of the Fours are shown to be well explained by the TSDPs.

\section{Price Differentials (P-Differentials) and CRiPS Analysis}

In this section, we first define the CRiPS (credit risk price spread) measure that shows P-differentials (in euros) of each GB of the Four States (France, Italy, Spain, Greece) relative to the corresponding DGB-equivalent bond of the same maturity and coupon rate. Secondly from the CRiPS analysis we draw some empirical observations concerning the differences of CRiPS of the Four States.

To define our CRiPS measure, it is noted that a $k \mathrm{~GB}$ price and a corresponding DGB price cannot be directly compared where $k=\mathrm{F}, \mathrm{I}, \mathrm{S}$ and $\mathrm{Gr}$, since bonds carry such attributes as maturity and coupon rate. Hence for each fixed month we define a measure of DGB-equivalent bond of $k \mathrm{~GB}(g)$ by

$$
\hat{P}_{g}^{k / D}=\sum_{j=1}^{M^{k}(g)} C_{g}^{k}\left(s_{g j}^{k}\right) \bar{D}^{D}\left(s_{g j}^{k}\right),
$$

where $\bar{D}^{D}(s)$ is the mean discount function estimated through the DGB pricing model in Sect. 3 with the set of cross-sectional DGB prices and $\left\{C_{g}^{k}\left(s_{g j}^{k}\right): j=\right.$ $\left.1,2, \ldots, M^{k}(g)\right\}$ is the CFs of coupons and principal 100 (euros) of the $k \mathrm{~GB}(g)$. Using DGB-equivalent bond, we define the CRiPS between the $k \mathrm{~GB}(g)$ and the DGBequivalent by

$$
y_{g}^{k}=P_{g}^{k}-P_{g}^{k / D}
$$

where $P_{g}^{k}$ is the $k \mathrm{~GB}(g)$ market price. The CRiPS measure $y_{g}^{k}$ is expected to be nonpositive, but since the GBs of different states are compared in our case, in the sub-period (a) where no credit differentiation is revealed, a few of $y_{g}^{k}$ 's are positive. An important feature of this measure is that it serves as a measure of credit risk and it is additive. In other words, a relative risk of a portfolio of FGB, IGB, SGB and GrGB is measured as

$$
R \equiv-\left\{\sum e_{g}^{F} y_{g}^{F}+\sum e_{g}^{I} y_{g}^{I}+\sum e_{g}^{S} y_{g}^{S}+\sum e_{g}^{G r} y_{g}^{G r}\right\}
$$

where $e_{g}^{k}$ is the number of units of the $k g \mathrm{~GB}$ included in the portfolio. If the risk of DGB per unit is zero up to 10 years, this is the risk volume of the portfolio in euros 

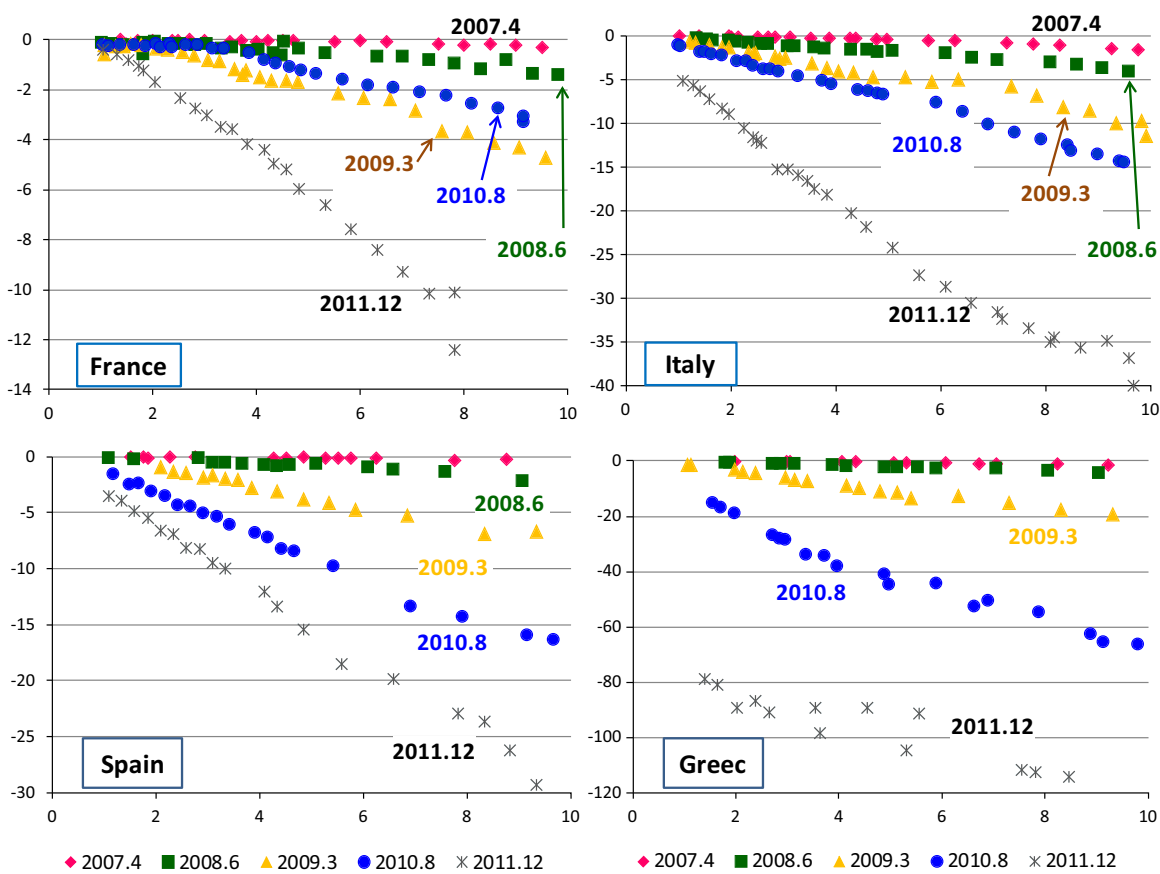

Fig. 7 The term structures of CRiPSs (TS-CRiPSs) in each state for 2007.4, 2008.6, 2009.3, 2010.8, 2011.3 and 2012.2

relatively to DGB. If the risk of the $g$ th DGB of maturity $s_{g M^{D}(g)}^{D}$ is represented by its TSDP $p^{D}(s)$, then the risk volume can be measured by

$$
z_{g}^{D}=100 \bar{D}^{D}\left(s_{g M^{D}(g)}^{D}\right) p^{D}\left(s_{g M^{D}(g)}^{D}\right)
$$

and hence the total risk volume in (4.3) plus risk volume of DGBs is

$$
U \equiv\left\{\sum e_{g}^{F} x_{g}^{F}+\sum e_{g}^{I} x_{g}^{I}+\sum e_{g}^{S} x_{g}^{S}+\sum e_{g}^{G r} x_{g}^{G r}\right\}+\sum e_{g}^{D} z_{g}^{D}
$$

where $x_{g}^{k}=-y_{g}^{k}+z_{g}^{D}$ with $k=\mathrm{F}, \mathrm{I}, \mathrm{S}, \mathrm{Gr}$.

Now using CRiPSs in (4.2), let us make an empirical credit study on all the GB prices $\left\{P_{g}^{k}: g=1, \ldots, G^{k}\right\}$ in each month issued by the $k$ th state for the period 2007.4-2012.3, where $k=$ F, I, S, Gr. In Fig. 7, within each state $k$, we make some time series comparisons of the term structures of the CRiPSs. Selecting the five time points; 2007.4, 2008.6, 2009.3, 2010.8, and 2011.12, we plot $\left(s_{g M^{k}(g)}^{k}, y_{g}^{k}\right)$ 's in 2-dim plane for each state, where $s_{g M^{k}(g)}^{k}$ is the maturity of the $k \mathrm{~GB}(g), g=1, \ldots, G^{k}$ and $G^{k}$ is the sample size of the $k$ GBs given in Table 1 . The horizontal axis and vertical axis respectively represent the maturity $s_{g M^{k}(g)}^{k}$ in years and CRiPS $y_{g}^{k}$ in euros. Note that the scale of the vertical axis in each state is different. 
Table 1 Sample sizes of each cross-sectional data set of GBs for each state over 2007.4-2012.3

\begin{tabular}{|c|c|c|c|c|c|c|c|c|c|c|c|c|c|c|c|}
\hline & $07-4$ & $07-5$ & $07-6$ & $07-7$ & $07-8$ & $07-9$ & $07-10$ & $07-11$ & $07-12$ & $08-1$ & $08-2$ & $08-3$ & $08-4$ & $08-5$ & $08-6$ \\
\hline Germany & 35 & 36 & 36 & 35 & 35 & 36 & 35 & 36 & 36 & 36 & 36 & 37 & 36 & 37 & 37 \\
\hline France & 36 & 37 & 38 & 37 & 37 & 37 & 36 & 36 & 35 & 36 & 36 & 36 & 36 & 37 & 37 \\
\hline Italy & 30 & 29 & 28 & 29 & 30 & 29 & 30 & 31 & 31 & 31 & 31 & 31 & 32 & 32 & 31 \\
\hline Spain & 16 & 16 & 16 & 16 & 16 & 16 & 16 & 15 & 15 & 16 & 16 & 15 & 15 & 15 & 15 \\
\hline \multirow[t]{2}{*}{ Greece } & 16 & 17 & 17 & 17 & 17 & 17 & 17 & 16 & 16 & 17 & 17 & 18 & 17 & 18 & 18 \\
\hline & $08-7$ & $08-8$ & $08-9$ & $08-10$ & $08-11$ & $08-12$ & $09-1$ & $09-2$ & $09-3$ & $09-4$ & $09-5$ & $09-6$ & $09-7$ & $09-8$ & $09-9$ \\
\hline Germany & 36 & 36 & 37 & 36 & 37 & 37 & 36 & 36 & 37 & 36 & 38 & 37 & 36 & 36 & 37 \\
\hline France & 37 & 37 & 36 & 36 & 36 & 36 & 36 & 36 & 36 & 35 & 36 & 38 & 37 & 37 & 36 \\
\hline Italy & 31 & 32 & 32 & 33 & 32 & 32 & 32 & 33 & 32 & 33 & 33 & 34 & 35 & 34 & 35 \\
\hline Spain & 14 & 14 & 15 & 16 & 16 & 16 & 17 & 17 & 17 & 17 & 18 & 18 & 19 & 19 & 19 \\
\hline \multirow[t]{2}{*}{ Greece } & 18 & 18 & 18 & 18 & 18 & 18 & 19 & 21 & 21 & 21 & 20 & 20 & 20 & 20 & 20 \\
\hline & $09-10$ & $09-11$ & 09-12 & $10-1$ & $10-2$ & $10-3$ & $10-4$ & $10-5$ & $10-6$ & $10-7$ & $10-8$ & $10-9$ & $10-10$ & $10-11$ & $10-12$ \\
\hline Germany & 36 & 38 & 37 & 38 & 39 & 38 & 39 & 39 & 38 & 37 & 39 & 39 & 38 & 40 & 39 \\
\hline France & 35 & 34 & 35 & 35 & 36 & 36 & 27 & 29 & 30 & 28 & 28 & 27 & 26 & 26 & 26 \\
\hline Italy & 35 & 35 & 36 & 37 & 36 & 36 & 36 & 37 & 38 & 38 & 38 & 37 & 38 & 39 & 39 \\
\hline Spain & 20 & 20 & 20 & 21 & 22 & 23 & 23 & 22 & 23 & 24 & 23 & 23 & 23 & 23 & 23 \\
\hline \multirow[t]{2}{*}{ Greece } & 20 & 21 & 21 & 22 & 22 & 23 & 23 & 21 & 21 & 22 & 21 & 21 & 21 & 21 & 21 \\
\hline & $11-1$ & $11-2$ & $11-3$ & $11-4$ & $11-5$ & $11-6$ & $11-7$ & $11-8$ & $11-9$ & $11-10$ & $11-11$ & $11-12$ & $12-1$ & $12-2$ & $12-3$ \\
\hline Germany & 40 & 41 & 40 & 41 & 42 & 42 & 40 & 42 & 41 & 41 & 42 & 41 & 41 & 41 & 40 \\
\hline France & 26 & 26 & 26 & 25 & 26 & 27 & 26 & 26 & 25 & 24 & 24 & 23 & 22 & 23 & 23 \\
\hline Italy & 39 & 39 & 39 & 39 & 40 & 40 & 40 & 41 & 41 & 40 & 41 & 40 & 41 & 41 & 42 \\
\hline Spain & 24 & 24 & 23 & 24 & 23 & 23 & 23 & 23 & 23 & 23 & 22 & 22 & 22 & 21 & 21 \\
\hline Greece & 21 & 21 & 20 & 19 & 18 & 18 & 18 & 18 & 17 & 16 & 16 & 15 & 17 & 16 & 4 \\
\hline
\end{tabular}

From Fig. 7 the following observations can be made.

(1) In each state the CRiPS graph at each time is almost linear, implying a legitimacy of the definition of CRiPS measure.

(2) Except for France, the almost linear CRiPS graphs are ordered from up to down in the order of 2007.4, 2008.6, 2009.3, 2010.8, and 2011.12. This means that along with these time points the slopes of the term structures of CRiPSs (TS-CRiPSs) become steeper and the credit risks of these states worsened relative to those of Germany. In case of France, the TS-CRiPS of 2009.3 is uniformly lower than that of 2010.8 and so the credit of FGB is improved from 2009.3 to 2010.8.

(3) In each state the slope of the TS-CRiPS of 2011.12, which is the mid of the Euro Crisis, is not only larger (in absolute value) than that of any other time but also it jumps down significantly from the slope of the TS-CRiPS of 2010.8. In 2011.12 

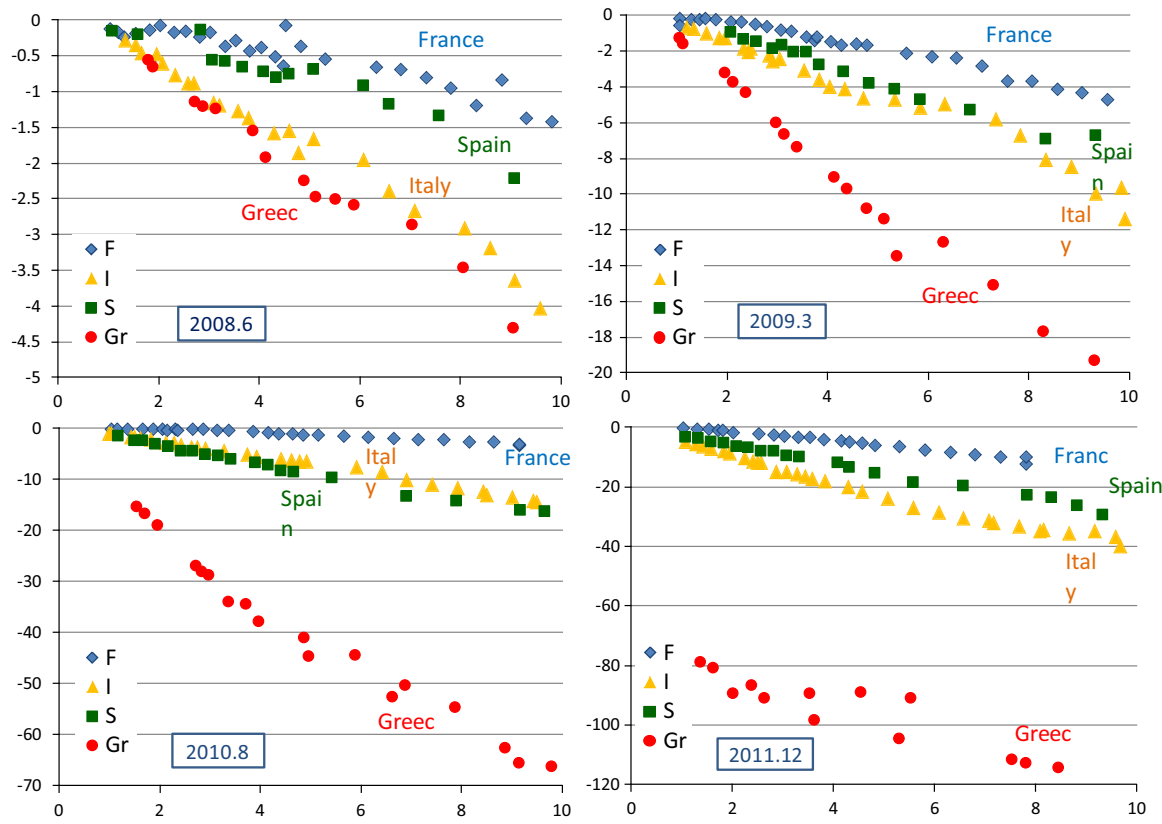

Fig. 8 TS-CRiPSs of France, Italy, Spain and Greece in 2008.6, 2009.3, 2010.8 and 2011.12

the 8 year CRiPS of FGB is about -12 euros, while the 9 year CRiPSs of Italy and Spain are respectively about -35 and -30 euros.

(4) In 2007.4, though the Italian CRiPSs are a bit negatively larger in the maturities of longer terms, all the CRiPSs are rather close to 0 even in Greece, meaning no significant credit differentiation at this time.

(5) In 2008.6 just before the subprime shock, the graph moves downward in each state but not much, implying that credit risks of these states are slightly larger than risk of Germany. For example, even the 10 year CRiPS of France is close to -2 euros, while that of Italy is close to -5 euros

(6) But in 2009.3 of the financial crisis, it moves downward significantly in each state. The 10 year CRiPSs of France, Italy, Spain and Greece are respectively about $-5,-12,-7.5$ and -20 euros, far away from DGB-equivalents.

In Fig. 8, for each of 2008.6, 2009.3, 2011.12 and 2011.12 the TS-CRiPSs (term structures of CRiPSs) of the Four States are plotted. This Fig directly compares the differences of the TS-CRiPSs in each time.

In 2008.6 the TS-CRiPS of Spain is close and similar to that of France though the latter is slightly and uniformly smaller in absolute value in the longer terms. On the other hand, the TS-CRiPS of Greece is close and similar to that of Italy though the latter is slightly and uniformly smaller in absolute value in the longer terms. Clearly the CRiPSs of Italy and Greece are separately larger in absolute value than those of France and Spain. This fact is probably related to the fact that the debt/GDP ratios of Italy and Greece are larger. In 2009.3 the TS-CRiPS of Spain goes down away from that of France and gets close to that of Italy and the 8.3 year CRiPS measure of Spain 
becomes about -7 euros. In 2010.8 the TS-CRiPS of Spain gets worse than that Italy and the 9.3-year CRiPS measure of Spain becomes about - 16.5 euros, which is significantly different from that of Germany. On the other hand, the 9-year CRiPS of France is about -3.3 euros, though it gets worse in 2012.2.

In the next section these observations are substantiated by introducing CB-pricing model and CRiPS measures are transformed into default probabilities of $k \mathrm{~GB}(g) \mathrm{s}$.

\section{Term Structures of Default Probabilities (TSDPs) of FGB, IGB, SGB and GrGB}

In this section we derive the (relative) TSDPs of each state up to 10 years via Kariya (2013) model, and then compare their time series movements of the TSDPs over the period 2007.4-2012.3. In Sect. 6 we will associate the TSDPs with the IR-differentials and relate them to the Maastricht condition (5) in Sect. 2.

We first briefly review our model. In the same way as in the case of GB model in Sect. 3, let $P_{g}^{k}$ denote the $k \mathrm{~GB}(g)$ price where time is fixed and let our model for $\left\{P_{g}^{k}: g=1, \ldots, G^{k}\right\}$ with $k=\mathrm{F}, \mathrm{I}, \mathrm{S}$ and $\mathrm{Gr}$ be denoted by

$$
P_{g}^{k}=\sum_{j=1}^{M^{k}(g)} \bar{C}_{g}^{k}\left(s_{g j}^{k}\right) D\left(s_{g j}^{k}\right)
$$

where $\left\{\bar{C}_{g}^{k}\left(s_{g j}^{k}\right)\right\}$ is the defaultable CFs of $k \mathrm{~GB}(g)$, which is specified below, $D\left(s_{g j}^{k}\right)$ is an attribute-dependent stochastic discount function and $s_{g j}^{k}$ is the future time at which the $j$ th $\mathrm{CF}$ of $k \mathrm{~GB}(g)$ is generated. Then by $D_{g}^{k}(s)=\bar{D}(s)+\Delta_{g}^{k}(s)$ as in (3.2), the model is expressed as

$$
P_{g}^{k}=\sum_{j=1}^{M^{k}(g)} \bar{C}_{g}^{k}\left(s_{g j}^{k}\right) \bar{D}\left(s_{g j}^{k}\right)+\varepsilon_{g}^{k} \text { with } \varepsilon_{g}^{k}=\sum_{j=1}^{M^{k}(g)} \bar{C}_{g}^{k}\left(s_{g j}^{k}\right) \Delta_{g}^{k}\left(s_{g j}^{k}\right) .
$$

It is noted that the mean discount function $\bar{D}(s)$ is common to all the $k \mathrm{~GB}(g) \mathrm{s}(g=$ $\left.1, \ldots, G^{k} ; k=\mathrm{F}, \mathrm{I}, \mathrm{S}, \mathrm{Gr}\right)$ because their prices are commonly denominated in euros. For $\bar{D}(s)$, we use the mean discount function $\bar{D}^{D}(s)$ estimated by the DGB prices since DGBs are regarded as the least risky GBs in our setting. A main feature differentiating this model from the GB model in Sect. 3 is the CF function $\bar{C}_{g}^{k}\left(s_{g j}^{k}\right)$ because the scheduled CFs are not fully guaranteed when the issuer of the GB gets defaulted. Here as expectations of investors, the $\mathrm{CF}$ at $s_{g j}^{k}$ is specified as

$$
\bar{C}_{g}^{k}\left(s_{g j}^{k}\right)=C_{g}^{k}\left(s_{g j}^{k}\right)\left[1-p^{k}\left(s_{g j}^{k}\right)\right]+100 \gamma^{k}\left[p^{k}\left(s_{g j}^{k}\right)-p^{k}\left(s_{g j-1}^{k}\right)\right],
$$

where $p^{k}(s)=P\left(\tau^{k} \leq s\right)$ is the (accumulated) default probability up to time $s$ with $\tau^{k}$ the default time of the $k$ th state and $\gamma^{k}$ is an expected recovery rate when the issuer 
gets defaulted. We view this CF function as the expected future CF at each $s_{g j}^{k}$ that acute investors form, by which we tacitly avoided the correlation problem between default event and interest rates.

The first term of the right side in (5.3) is coupon times non-default probability and the second term is the CF when the issuer gets defaulted within the period $\left(s_{g j-1}^{k}, s_{g j}^{k}\right]$, which is the principal 100 times the recovery rate $\gamma^{k}$ multiplied by the default probability in the period $\left(s_{g j-1}^{k}, s_{g j}^{k}\right]$. The TSDP of the $k \mathrm{~GB}$ is given by the accumulated default probability function $p^{k}(s)$ with $0<s \leq 10$. For simplicity let $p^{k}(s)$ be approximated uniformly by a polynomial of $\operatorname{order} q$;

$$
p^{k}(s)=\alpha_{1}^{k} s+\alpha_{2}^{k} s^{2}+\cdots+\alpha_{q}^{k} s^{q} .
$$

In our analysis, taking the fact of small samples into account, we commonly assume $q=5$ based on the AIC and the average values of the minimized objective functions of the Four States, though the AIC slowly decreases even after $q=5$. Then inserting (5.3) and (5.4) into (5.2) yields

$$
y^{k}=X^{k} \beta^{k}+\varepsilon^{k}
$$

for each state (see Kariya et al. 2012 for details), where $\beta^{k}=\left(\alpha_{1}^{k}, \ldots, \alpha_{q}^{k}\right)^{\prime}$ is estimated by the GLS method. It is noted that the $g$ th element of the explained vector $y_{k}$ turns out to be the $k$ th CRiPS measure;

$$
y_{g}^{k}=P_{g}^{k}-\hat{P}_{g}^{k / D} \text { with } \hat{P}_{g}^{k / D}=\sum_{j=1}^{M^{k}(g)} C_{g}^{k}\left(s_{g j}^{k}\right) \bar{D}^{D}\left(s_{g j}^{k}\right) .
$$

The covariance structure is similar to the GB model case in Sect. 3 though it contains $\beta^{k}$ and is given in Appendix A. Clearly each TSDP is obtained through (5.4) by estimating $\beta^{k}$ in (5.5) for each month.

In the sequel the recovery rate $\gamma^{k}$ is assumed to be zero because it is difficult to identify it for each state and the assumption makes us lead to a common base to compare the TSDPs over different states. In addition it is remarked that the actual recovery rate of each state is not only different but also very uncertain and stochastic at each time.

In Fig. 9 the TSDPs of each state are graphed, where the vertical axis is DP. From these graphs it is observed:

(1) Though the levels of DPs $\left\{p^{k}(s)\right\}$ for each state are different where $s=$ $1,2, \ldots, 10$, the patterns of time path of each $p^{k}(s)$ over the sample period are similar. All the DPs of the Four States are getting larger relatively to their past DPs over the period.

(2) This implies that only Germany has a sound credit position over the period, which was observed in terms of IR-differentials in Sect. 3 as well as P-differentials in Sect. 4. 

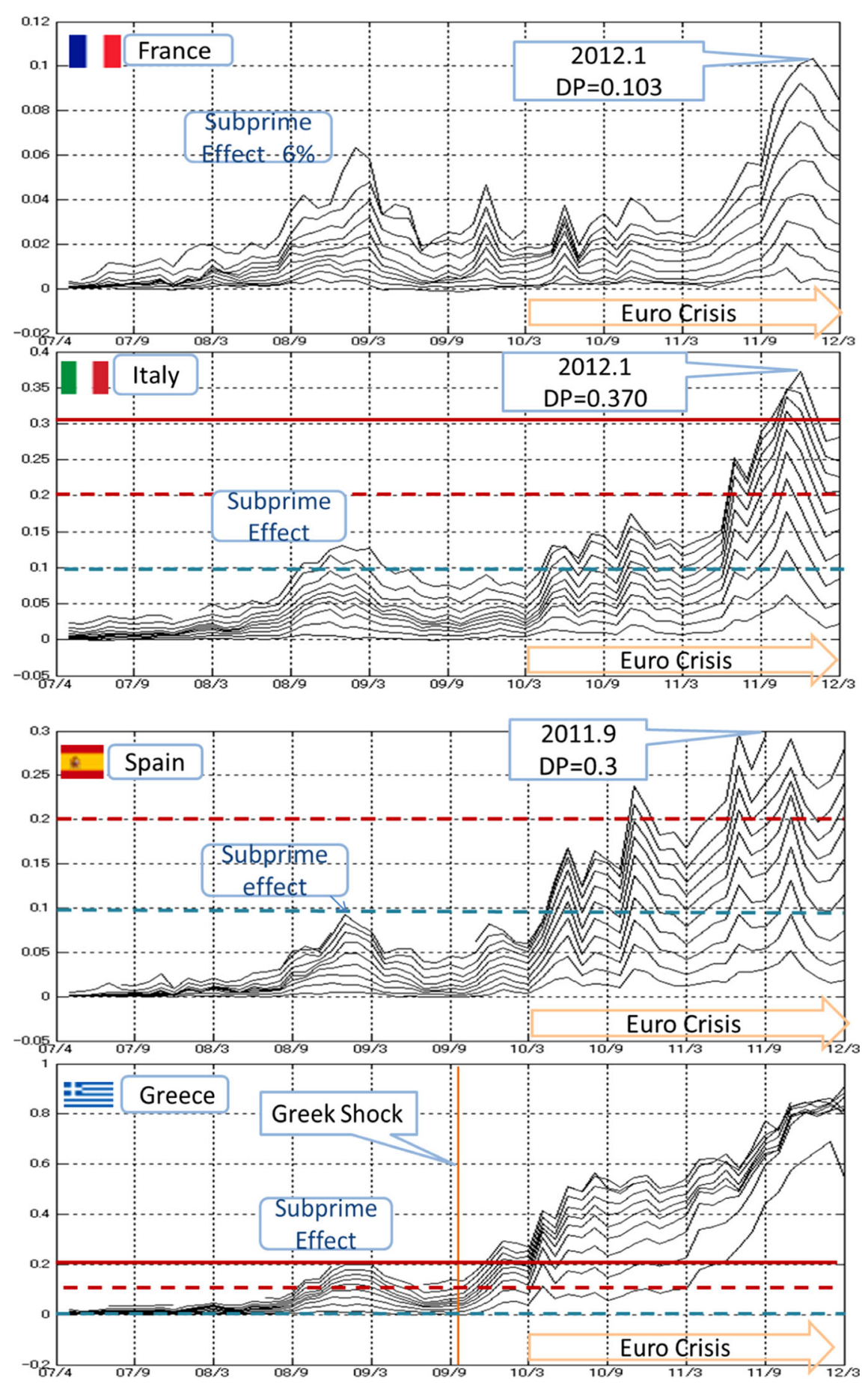

Fig. 9 The TSDPs $\left\{p_{k}(s): s=1,2, \ldots, 10\right\}$ of France, Italy, Spain and Greece over the sample period 2007.4-2012.3 


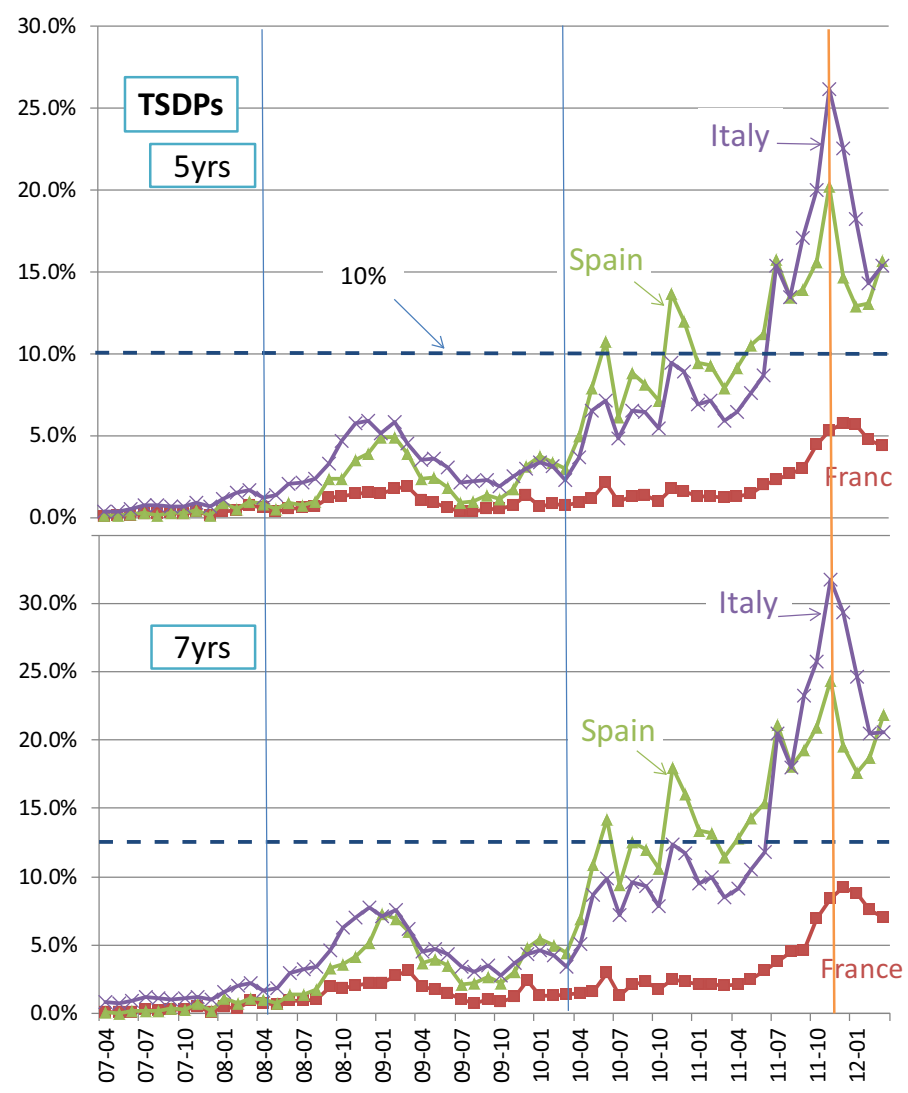

Fig. 10 Graphs of DPs $p^{k}(5)$ and $p^{k}(7)$ for $k=\mathrm{F}, \mathrm{I}, \mathrm{S}$

(3) Overall the 8-year DP $p^{F}$ (8) of France takes $10.3 \%$ at its maximum in 2012.1. In 2012.1 S\&P downgraded the rating of 9 Euro GBs including FGB. It is noted that FGBs of 10-year maturity disappear after 2010.3 and the FRBs of 9-year maturity disappear after 2011.3 because their GBs are not available in the market.

(4) On the other hand, the 10-year DP $p^{I}(10)$ of Italy takes $37 \%$ at its maximum in 2011.12, the 10-year DP $p^{S}(10)$ of Spain takes $30 \%$ at its maximum in 2011.9 but the Greek case is as catastrophically large as $80 \%$.

(5) Around the financial crisis period 2008.9-2009.3, the TSDPs $\left\{p^{k}(s): s=\right.$ $1,2, \ldots, 10\}$ shift above for each state $k$. But the effect is different among the states and the local maximum of 10-year DPs $p^{k}(10)^{\prime} s$ around that period is about $6 \%$ in France, about $13 \%$ in Italy, about $10 \%$ in Spain and about $20 \%$ in Greece, the last of which is already the largest.

(6) In the sub-period 2007.4-2008.6, the 10-year DPs $p^{I}$ (10)'s of Italy are larger than those of France and Spain, which will probably reflect the high debt/GDP ratios of Italy even in the sub-period.

In Fig. 10 the time paths of 7-year DPs $\left\{p^{k}(7)\right\}$ and 5-year DPs $\left\{p^{k}(5)\right\}$ are graphed for France, Italy and Spain. Here the scale of the vertical axis for DP is the same and 


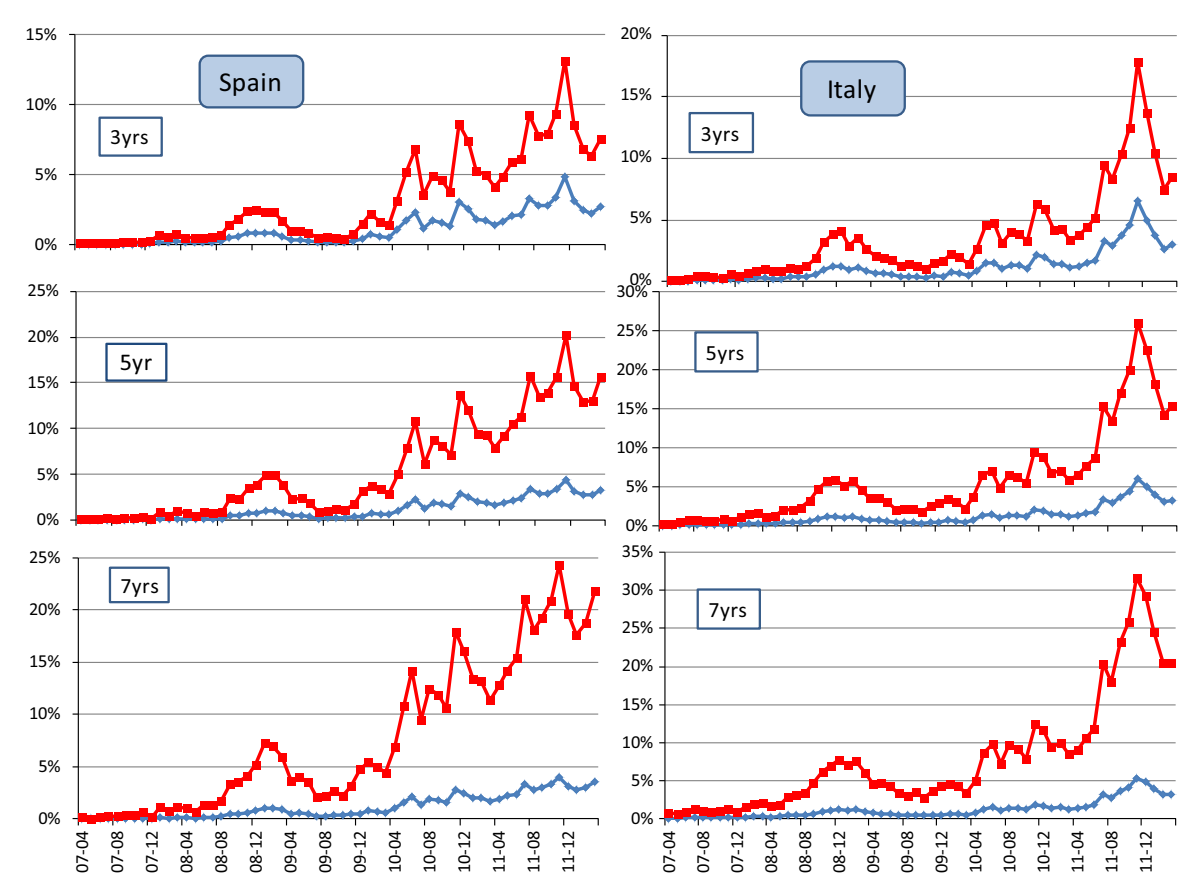

Fig. 11 Graphs of $p^{k}(s)$ and $\delta^{k}(s) \equiv r^{k}(s)-r^{D}(s)$ for $k=\mathrm{I}, \mathrm{S}$ and $s=3,5,7$

so direct comparisons of the DP levels for each time can be made. Clearly from the start of the Euro Crisis in 2010.3 the DPs of Italy and Spain deviate from those of France rapidly and $p^{I}(7)$ and $p^{S}(7)$ reach such a large level as 30 and $25 \%$ at the end of 2011, though the Italian DP $p^{I}(7)$ is deviating from that of the Spanish DP $p^{S}(7)$ in 2011. On the other hand, the French DP $p^{F}$ (7) reaches $10 \%$ in 2011.12, implying a large deviation from that of Germany.

In the next section we relate these results on DPs to the results on the IR-differentials and discuss on the Maastricht condition (5) in terms of DPs.

\section{Default Probabilities (DPs), IR-Differentials and Maastricht Condition (5)}

The relationship between the IR-differentials and the DPs is explored by regression analysis in this section and the result is associated with the Maastricht condition (5) on the IR-gaps for a new state to participate in the EEMU. The IR-differential of $s$-year maturity between the $k$-IR and the D-IR is of course defined as $r^{k}(s)-r^{D}(s)$, where $k=\mathrm{F}, \mathrm{I}, \mathrm{S}$ and $\mathrm{Gr}$.

In Fig. 11 the time series graphs of the IR differentials and DPs of Italy and Spain among others are plotted for $s=3,5,7$. It is observed that the IR differentials and the DPs fluctuate together in every detail, though the fluctuations of the IR-differentials may not be easily seen in details.

To relate the IR-differential with the DP, we regress $p^{k}(s)$ on $\delta^{k}(s) \equiv r^{k}(s)-r^{D}(s)$ by the model over the period; 
Table 2 Results of regression analysis between the DPs $\left\{p^{k}(s)\right\}$ and the IR-differentials $\left\{\delta^{k}(s) \equiv r^{k}(s)-\right.$ $\left.r^{D}(s)\right\}$ for 2004.4-2012.3

\begin{tabular}{lllllll}
\hline & & $\beta$ & $(\mathrm{t}-\mathrm{value})$ & $\alpha$ & (t-value) & adj $\mathrm{R}^{2}$ \\
\hline France & $2 \mathrm{yrs}$ & 2.001 & $(122.06)$ & 0.00003 & $(0.76)$ & 0.996 \\
& $3 \mathrm{yrs}$ & 2.936 & $(92.99)$ & 0.00014 & $(1.43)$ & 0.993 \\
& $5 \mathrm{yrs}$ & 4.830 & $(74.19)$ & 0.00045 & $(1.75)$ & 0.989 \\
& $7 \mathrm{yrs}$ & 6.642 & $(73.77)$ & 0.00083 & $(1.99)$ & 0.989 \\
\multirow{5}{*}{ Spain } & $9 \mathrm{yrs}$ & 8.440 & $(21.60)$ & 0.00137 & $(1.34)$ & 0.919 \\
& $2 \mathrm{yrs}$ & 1.908 & $(339.37)$ & 0.00049 & $(5.72)$ & 0.999 \\
& $3 \mathrm{yrs}$ & 2.784 & $(225.66)$ & 0.00103 & $(5.33)$ & 0.999 \\
& $5 \mathrm{yrs}$ & 4.675 & $(225.65)$ & 0.00107 & $(3.16)$ & 0.999 \\
& $7 \mathrm{yrs}$ & 6.199 & $(158.86)$ & 0.00359 & $(5.57)$ & 0.998 \\
& $9 \mathrm{yrs}$ & 7.747 & $(136.45)$ & 0.00491 & $(5.24)$ & 0.997 \\
& $2 \mathrm{yrs}$ & 1.904 & $(297.66)$ & 0.00041 & $(3.70)$ & 0.999 \\
& $3 \mathrm{yrs}$ & 2.733 & $(168.47)$ & 0.00268 & $(9.18)$ & 0.998 \\
& $5 \mathrm{yrs}$ & 4.440 & $(181.03)$ & 0.00292 & $(6.56)$ & 0.998 \\
& $7 \mathrm{yrs}$ & 6.089 & $(142.95)$ & 0.00289 & $(3.85)$ & 0.997 \\
& $9 \mathrm{yrs}$ & 7.206 & $(85.37)$ & 0.01311 & $(8.92)$ & 0.992 \\
& $2 \mathrm{yrs}$ & 1.009 & $(35.24)$ & 0.03599 & $(4.68)$ & 0.955 \\
& $3 \mathrm{yrs}$ & 1.475 & $(29.82)$ & 0.04785 & $(4.93)$ & 0.938 \\
& $5 \mathrm{yrs}$ & 2.636 & $(33.80)$ & 0.04906 & $(5.24)$ & 0.951 \\
& $7 \mathrm{yrs}$ & 3.248 & $(25.82)$ & 0.07019 & $(5.45)$ & 0.919 \\
& $9 \mathrm{yrs}$ & 5.204 & $(41.15)$ & 0.04591 & $(5.75)$ & 0.969 \\
\hline
\end{tabular}

$$
p^{k}(s)=\alpha^{k}(s)+\beta^{k}(s)\left[r^{k}(s)-r^{D}(s)\right]
$$

for each state $k=\mathrm{F}, \mathrm{I}, \mathrm{S}, \mathrm{Gr}$, where $s=2, \ldots, 9$. The result is summarized in Table 2, where the analysis is based on \% unit. Not only all the $t$-values of the coefficients $\beta^{k}(s)$ 's are very significant but also the adjusted $R^{2}$ 's are all more than 0.9. In fact, except for the cases of the 9-year French DP $p^{F}$ (9) and Greek DPs, all the adjusted $R^{2}$ 's are more than 0.989 , showing the strongly linear relationships between the IRdifferentials and the DPs. In particular, the linearity is very strong in the cases of Italy and Spain. In addition, all the $\beta^{k}(s)$ 's are greater than 1 and increasing in $s=2, \ldots, 9$ for each $k$, which implies that the larger the maturity of the IR-differential, the lager the magnifying regression coefficient $\beta^{k}(s)$ is. The constant terms $\alpha^{k}(s)$ 's are very small but they are all significant in $t$-values except for the France models.

Using the almost perfect linearity, the IR-differential $\delta^{k}(s) \equiv r^{k}(s)-r^{D}(s)$ is expressed as

$$
\begin{aligned}
r^{k}(s) & =r_{k}^{D}(s)+\lambda^{k}(s) p^{k}(s)-\kappa^{k}(s) \\
& \simeq r^{D}(s)+\lambda^{k}(s) p^{k}(s)
\end{aligned}
$$

where $\lambda^{k}(s)=1 / \beta^{k}(s)$ and $\kappa^{k}(s)=\alpha^{k}(s) / \beta^{k}(s) \simeq 0$. Hence $\lambda^{k}(s) p^{k}(s)$ corresponds to the IR-differential relative to the German IR $r^{D}(s)$ for each $s$. 
Now in the Maastricht condition (5) on IR-differential requires that a new state that intends to participate in the EEMU is required to meet the condition that its IRdifferential of 10-year maturity compared to the average of the lowest three 10-year IRs in the EEMU is less than $2 \%$. In this paper the average rate is regarded as the D-IR and we substitute the 10 -year rate $r^{k}(10)$ by $r^{k}(9)$. Then since $\lambda^{k}(s) p^{k}(s)$ is the IR-differential, the c\% rule is

$$
\lambda^{k}(s) p^{k}(s) \leq c \% \text { or equivalently } p^{k}(s) \leq c \beta^{k}(s) \%
$$

Thus the default probability should be less than or equal to $c \beta^{k}(s)$. If $c=2, k=\mathrm{I}$ and $s=7$, then $\beta^{I}(9)=7.2$ and so $c \beta^{I}(9)=2 \times 7.2=14.4$, implying that the DP $p^{I}(9)$ should be less than $14.4 \%$. However, in case of Italy DP(7) goes over $30 \%$ in 2011 and so the condition is not satisfied. Also in case of Spain DP(7) goes far over the threshold required in the Maastricht condition.

It is remarked that the linear relationship does not accidentally hold but can be shown to hold structurally in the relation of the bond pricing model in Sect. 3 and the credit risk model in Sect. 5 though we do not show it here. In other words, the credit risk measures of the DP and the IR-differential are almost equivalent.

\section{CDSs and DPs: Effectiveness of Our DP Measures}

As is well known, a CDS here is the credit derivative which pays its holder the GB principal in US dollars when the issuer of the GB gets defaulted. Note that the issuers of CDSs are investment bankers, hedge funds, insurance companies, etc. and hence they may be different from bond investors. In this section, to show the effectiveness of the DP measures and related analyses in this paper, we associate our DP measures of each maturity for each state with the CDSs of the same maturity for the same state. For this purpose we regress CDS prices (premiums) on levels of DPs and slopes of TSDPs derived in Sect. 5 and show that CDS prices are well explained by those variables.

Let $k C D S(j)$ variable denote the CDS price (premium) for the $k \mathrm{~GB}$ of $j$-year maturity and let $k D P(j)$ variable be the DP of the $k$-state up to $j$ years where $k=\mathrm{F}$, I, S. Our base model is the following regression model that explains $k C D S(j)$ by $k D P(j)$;

$$
\text { Model O } \quad k C D S(j)=\alpha^{k}(j)+\beta_{1}^{k}(j) k D P(j)+\varepsilon^{k}(j),
$$

which we call Base Model O.

The regression results for the FCDS, ICDS and SCDS are given in Table 3, where the sample period is 2009.1-2012.3. The results show:

(1) Except for the case of ICDS(10) all the regression coefficients are significant and the longer the maturities are, the less the coefficients and the larger the $t$-values are.

(2) Except for the cases of $I C D S(10)$ and $I C D(3)$, all the constant terms are significant and decreasing along the period of maturities. 


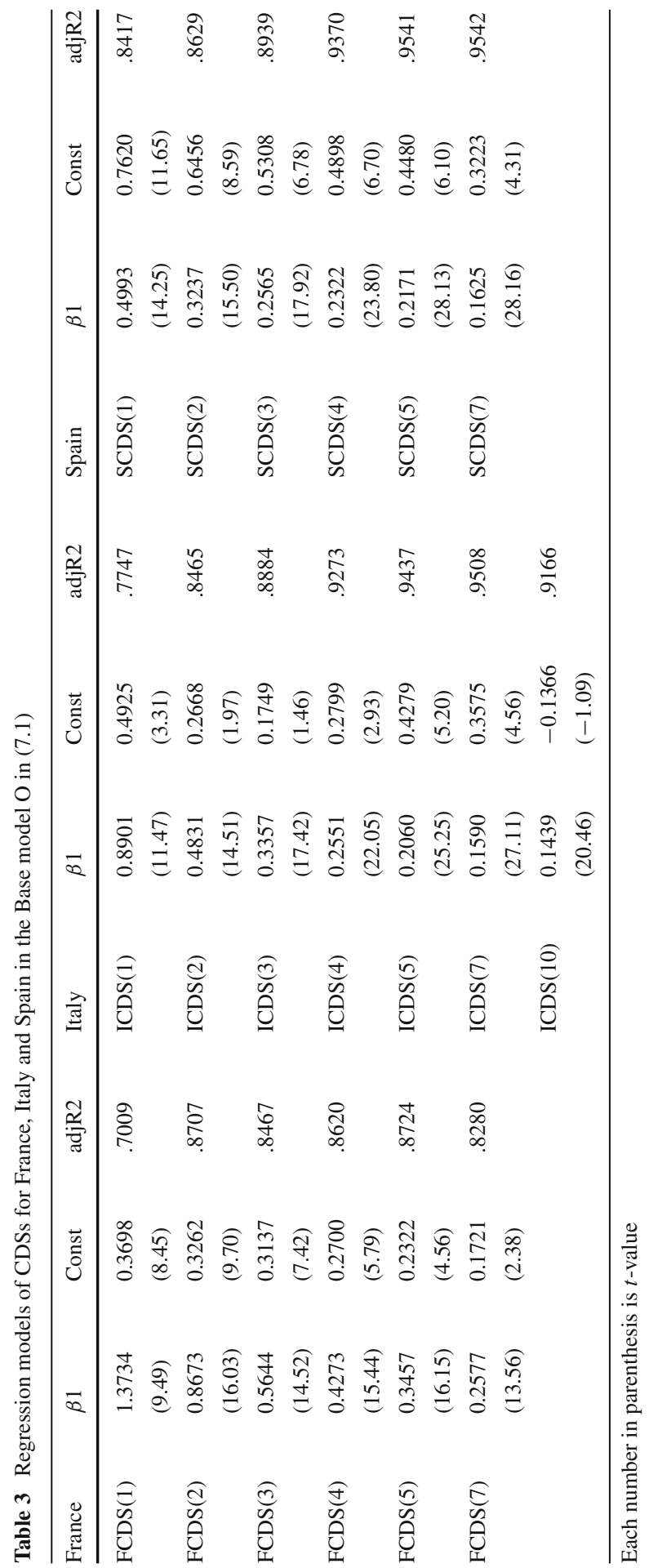


(3) In the cases of $I C D S(j), j=4,5,7,10$ and $S C D S(j), j=4,5,7$, the adjusted $R^{2}$ 's are greater than 0.9 and so in these cases each $k D P(j)$ derived from GB prices will be in a good correspondence with the corresponding $k C D S(j)$ in the derivative market for each time.

(4) In the case of the FCDSs, the adjusted $R^{2}$ of $F C D S(1)$ is the lowest as 0.7, the worst even in all the states, and the other adjusted $R^{2}$ 's are larger than 0.8 .

(5) In the case of the ICDSs, the adjusted $R^{2}$, s are increasing from $R^{2}(1)=0.77$ to $R^{2}(7)=0.95$ but in the case of $\operatorname{ICDS}(10), R^{2}(10)=0.92$, the constant term is negative and its t-value is insignificant.

(6) In the case of the SCDS, the least adjusted $R^{2}$ is 0.84 for $S C D S(1)$ and is monotonically increasing up to 0.95 for $S C D S(7)$. This case will be the best case among the three states so long as the base model is concerned.

Summarizing the results, the Base Model will be satisfactory for explaining CDSs by corresponding DPs except for $F C D S(1)$ and $I C D S(1)$.

Next we will improve on the above results by introducing the slope variables of TSDPs into the Base Model, where the slope is measured by the difference of two DPs in the curve of each TSDP. Among others, we consider the three models:

$$
\begin{aligned}
& \mathrm{A} k C D S(s)=\alpha^{k}(s)+\beta_{1}^{k}(s) D P^{k}(s)+\beta_{2}^{k}(s)\left(D P^{k}(5)-D P^{k}(2)\right)+\varepsilon^{k}(s) \\
& \mathrm{B} k C D S(s)=\alpha^{k}(s)+\beta_{1}^{k}(s) D P^{k}(s)+\beta_{2}^{k}(s)\left(D P^{k}(9)-D P^{k}(5)\right)+\varepsilon^{k}(s) \\
& \mathrm{C} k C D S(s)=\alpha^{k}(s)+\beta_{1}^{k}(s) D P^{k}(s)+\beta_{2}^{k}(s)\left(D P^{k}(9)-D P^{k}(2)\right)+\varepsilon^{k}(s)
\end{aligned}
$$

Model A uses the slope $\left(D P^{k}(5)-D P^{k}(2)\right) / 3$ of the $k$ th TSDP between 5-year term and 2-year term though $1 / 3$ is absorbed into $\beta_{2}^{k}(s)$. Similarly Model B and Model C use the slopes $\left(D P^{k}(9)-D P^{k}(5)\right) / 4$ and $\left(D P^{k}(9)-D P^{k}(2)\right) / 7$ of TSDPs respectively for Italy and Spain, but $\left(D P^{k}(8)-D P^{k}(5)\right) / 3$ and $\left(D P^{k}(8)-D P^{k}(2)\right) / 6$ of TSDP respectively for France due to the lack of FGBs with maturity more than 8 years.

In Table 4 the empirically best models in adjusted $R^{2}$ among Models A, B and C are selected for each $k C D S$. First note that except for $\operatorname{ICDS}(j), j=1,2,3$, all the coefficients of $\beta_{1}^{k}(j)$ 's are significant, implying the importance of the level variables of DPs.

The results are summarized;

(1) In the case of France, Model A improves Model O significantly for $F C D S(j)$, $j=1,2,3$, none of the three models cannot improve it for $F C D S(j), j=4,5$ and Model C improves it for $F C D S(7)$ in adjusted $R^{2}$ with the $t$-value of $\beta_{F 2}(7)$ significant. In the case of $F C D S(1)$ the adjusted $R^{2}$ changes from 0.7 to 0.9 when the slope variable is added to Model O. In Fig. 12 the improvement is visualized.

(2) In the case of Italy, Model A improves Model O for ICDS(j), $j=1,2,3,4$. But the $t$-values of $\beta_{1}^{I}(j)$ 's with $j=1,2,3$ become less than 2, though we keep the $D P(j)$ variables in our basic viewpoint. In Fig. 12 the improvement is visualized for $I C D S(1)$, where the adjusted $R^{2}$ changes from 0.77 to 0.87 . On the other hand, 
Table 4 Best regression results for France, Italy and Spain among Models A, B and C

\begin{tabular}{|c|c|c|c|c|c|c|c|c|c|c|c|}
\hline France & $\beta 1$ & $\beta 2$ & const & $\operatorname{adjR2}$ & Spain & \multicolumn{2}{|c|}{$\beta 1$} & \multicolumn{2}{|c|}{$\beta 2$} & const & $\operatorname{adjR}$ \\
\hline \multirow{2}{*}{$\mathrm{FCDS}(1) \mathrm{A}$} & 0.707 & 0.195 & 0.237 & \multirow{2}{*}{0.906} & \multirow{2}{*}{$\operatorname{SCDS}(1) A$} & \multirow{2}{*}{\multicolumn{2}{|c|}{$\begin{array}{l}0.200 \\
(4.70)\end{array}$}} & \multirow{2}{*}{\multicolumn{2}{|c|}{$\begin{array}{l}0.137 \\
(8.12)\end{array}$}} & 0.482 & \multirow{2}{*}{0.943} \\
\hline & (6.46) & $(9.05)$ & $(8.30)$ & & & & & & & (9.22) & \\
\hline \multirow{2}{*}{$\mathrm{FCDS}(2) \mathrm{A}$} & 0.559 & 0.138 & 0.269 & \multirow{2}{*}{0.903} & \multirow{2}{*}{$\operatorname{SCDS}(2) A$} & \multirow{2}{*}{\multicolumn{2}{|c|}{$\begin{array}{l}0.103 \\
(3.46)\end{array}$}} & \multirow{2}{*}{\multicolumn{2}{|c|}{$\begin{array}{l}0.171 \\
(8.22)\end{array}$}} & 0.399 & \multirow{2}{*}{0.951} \\
\hline & $(5.80)$ & (3.65) & (8.15) & & & & & & & (7.39) & \\
\hline \multirow{2}{*}{$\mathrm{FCDS}(3) \mathrm{A}$} & 0.348 & 0.154 & 0.270 & \multirow{2}{*}{0.861} & \multirow{2}{*}{$\operatorname{SCDS}(3) A$} & \multirow{2}{*}{\multicolumn{2}{|c|}{$\begin{array}{l}0.063 \\
(2.23)\end{array}$}} & \multicolumn{2}{|c|}{0.207} & 0.332 & \multirow{2}{*}{0.955} \\
\hline & (3.27) & (2.17) & $(6.00)$ & & & & & (7. & & (5.72) & \\
\hline \multirow{2}{*}{ FCDS(4)A } & 0.484 & -0.028 & 0.287 & \multirow{2}{*}{0.859} & \multirow{2}{*}{$\operatorname{SCDS}(4) A$} & \multicolumn{2}{|c|}{0.088} & \multicolumn{2}{|c|}{0.200} & 0.362 & \multirow{2}{*}{0.95} \\
\hline & $(4.28)$ & $(-0.52)$ & (5.01) & & & & 67) & (4. & 53) & (5.51) & \\
\hline \multirow{2}{*}{ FCDS(5)A } & 0.529 & -0.123 & 0.286 & \multirow{2}{*}{0.880} & \multirow{2}{*}{ SCDS(5)A } & & 127 & 0.1 & & 0.386 & \\
\hline & (5.18) & $(-1.83)$ & (4.98) & & & & 07) & (2. & & (5.14) & 0.95 \\
\hline & 0.632 & -0.387 & 0.273 & & & & 115 & 0.1 & & 0.333 & \\
\hline FCDS(7)C & $(5.70)$ & $(-3.42)$ & $(3.88)$ & 0.866 & SCDS(7)A & & 66) & (1. & & (4.44) & 0.95 \\
\hline Italy & $\beta 1$ & $\beta 2$ & const & $\operatorname{adj} R 2$ & & & & & & & \\
\hline & 0.121 & 0.330 & -0.124 & & France & & It & & & Spain & \\
\hline ICDS(1)A & $(0.82)$ & $(5.64)$ & $(-0.80)$ & 0.817 & FCDS(1) & A & ICD & & A & SCDS(1) & A \\
\hline & 0.101 & 0.300 & -0.022 & 0905 & FCDS(2) & A & ICD & & A & SCDS(2) & A \\
\hline ICDS(2)A & (1.23) & (4.91) & $(-0.18)$ & & FCDS(3) & A & ICD & & A & SCDS(3) & A \\
\hline & 0.098 & 0.265 & 0.040 & & FCDS(4) & 0 & ICD & & A & $\operatorname{SCDS}(4)$ & A \\
\hline ICDS(3)A & (1.47) & (3.69) & $(0.36)$ & 0 & FCDS(5) & 0 & ICD & & 0 & SCDS(5) & A \\
\hline & 0.205 & 0.117 & -0.103 & & FCDS(7) & C & ICD & & 0 & $\operatorname{SCDS}(7)$ & 0 \\
\hline ICDS(4)A & $(8.56)$ & $(2.37)$ & $(-0.56)$ & 0.9 & & & ICD & & 0 & & \\
\hline & 0.179 & 0.075 & 0.185 & & & & & & & & \\
\hline ICDS(5)A & $(9.32)$ & $(1.57)$ & $(1.06)$ & & & & & & & & \\
\hline & 0.163 & -0.012 & 0.394 & & Su & imá & ry & 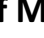 & 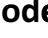 & Selec & \\
\hline ICDS(7)A & $(9.73)$ & $(-0.23)$ & (2.23) & & & & & & & - & \\
\hline & 0.164 & -0.071 & -0.010 & & & & & & & & \\
\hline ICDS(10)A & (6.73) & $(-0.85)$ & $(-0.05)$ & & & & & & & & \\
\hline
\end{tabular}

The models with shadows are not significant in the $t$-values of slope coefficients $\beta_{2}^{k}(s)$

none of the three models improve Model O significantly for $\operatorname{ICDS}(j), j=$ $5,7,10$ in terms of $t$-values of $\beta_{2}^{I}(j)$ or adjusted $R^{2}$.

(3) In the case of Spain, Model A improve Model O for $\operatorname{SCDS}(j), j=1,2,3,4,5$ but not for $\operatorname{SCDS}(j), j=7$.

Overall, for CDSs of shorter terms the base models are improved by introducing the slope variables of the TSDPs. The slope $\left(D P^{k}(7)-D P^{k}(2)\right) / 5$ of the full TSDPs makes an improvement on Base Model O of $F C D S(7)$, while the shorter slope $\left(D P^{k}(5)-D P^{k}(2)\right) / 3$ of TSDPs on Base Models of FCDS,ICDS and SCDS. From the significance of $t$-values for the slope variables and adjusted $R^{2}$, we summarize our model selection in the south-east corner of Table 4 where the DP variables are kept in the models even if the $t$-values are insignificant as in $\operatorname{ICDS}(j)$ with $j=1,2,3$.

It is noted that CDS markets exist as derivative markets for GBs and so they are closely related. But the players who form or quote CDS prices are not necessarily investors in the GB markets and GDS markets are rather smaller. Taking into this point account, our empirical result that the variations of $D P(j)$ variable and $C D S(j)$ variable are synchronized will imply that our method and model of deriving TSDPs are effective to a large extent. And the results will be used for making a certain decision on pricing CDSs and including CDSs for risk management in bond portfolios.

In Fig. 12 the graphs of FCDS(1)A, ICDS(1)A and SCDS(1)A show the improvements by introducing the TSDP slope variables in addition to the DP level variables, where the adjusted $R^{2}$ 's significantly increase. 

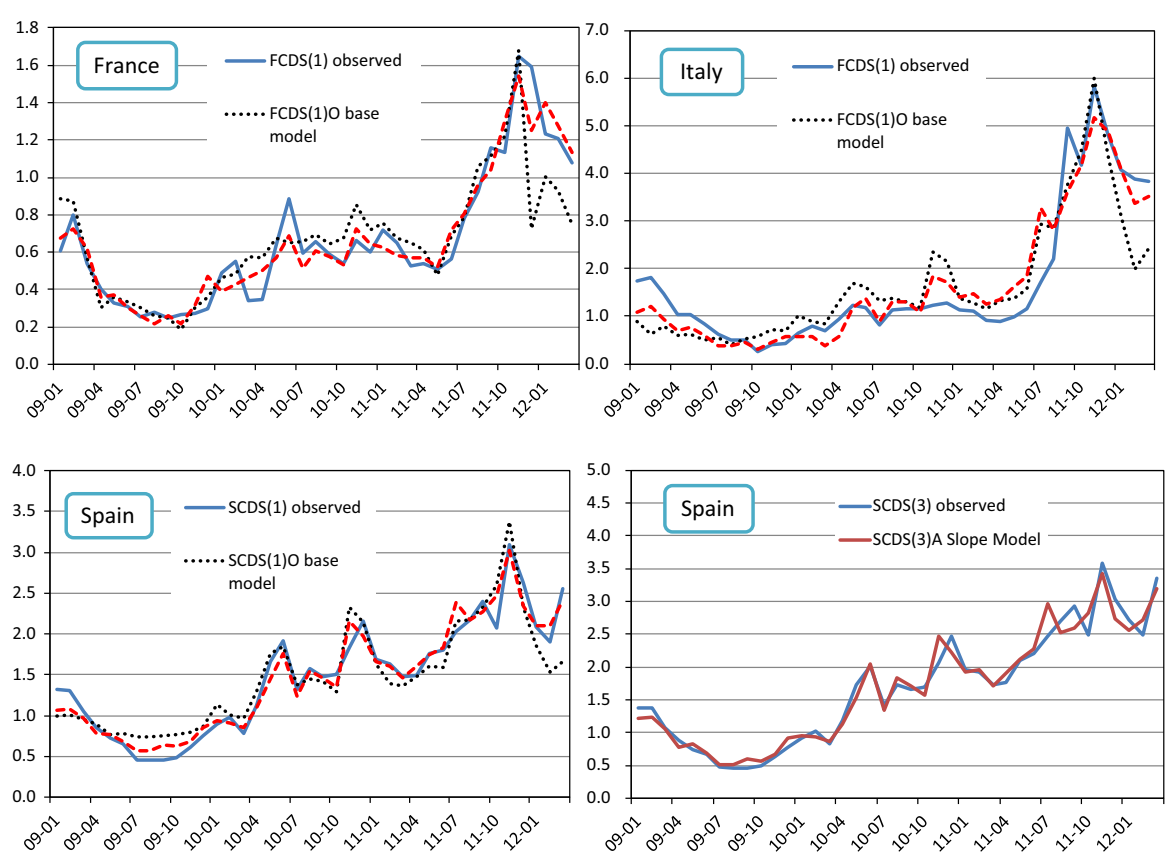

Fig. 12 CDSs are regressed on levels and slopes of TSDPs. In FCDS1 and ICDS1, the values of Model O and Model A with Observed values are plotted

It is remarked that the results on the high adjusted $R^{2}$ 's in Table 4 are overall results for the total period and may not be as effective as the apparent high numbers. In fact, the fluctuations in the graphs include a big trendy mountain (Euro Crisis) that may be under a long cycle as in Fig. 12. Hence so long as the regression models pick the big movements, the adjusted $R^{2}$ 's tend to be large. But this is a limitation of regression analysis itself and the results will still show the co-movements of the CDSs with the levels of the DPs and the slopes. In time series context the CDS, DP and Slope variables may be co-integrated to a certain degree, though we do not here explore for it. Note that the DPs and Slopes data are cross-sectionally derived data by our model.

\section{Conclusion}

We made a comprehensive credit risk analysis on FGB, IGB, SGB and GrGB via the IR-differentials, the GB price differentials, and the DPs in comparison with DGB where the sample period was 2007.4-2012.3. First after making some discussions and observations on the business cycles of the Five States and the Maastricht convergence condition of IRs, we derived the TSIRs via the bond-pricing model in KWWDY (2012) and compared them. In association with the budgetary conditions and business cycles of the Five States, we found that (a) in the sub-period 2007.4-2008.6 the TSIRs of the Five States moved together at almost same levels, meaning that no credit differentiation was found in the IR-differentials, (b) in the sub-period 2008.7-2010.3 all the IRs 
tended to decrease gradually as downward trend movements but their IR-differentials exhibited some credit differentiation, (c) in the sub-period 2010.4-2011.12 the IRdifferentials tended to diverge and (d) after that they tended to get stabilized gradually. Though the F-TSIRs moved together with the D-TSIR before the Euro Crisis, then they deviate. This deviation would have made the role of the German Government more important for the stability of the EEMU.

Secondly we proposed what we call CRiPS measure, which measures directly credit risk via the P-differential between a given GB and DGB-equivalent in terms of euros. The CRiPS measure is model-free once the mean discount function of Germany is estimated. In our empirical analysis the 10-year CRIPSs of Italy and Spain in the mid of the Financial Crisis 2009.3 were respectively about -10 euros and -7 euros, but in the mid of the Euro Crisis 2011.12 they jumped down to about -35 euros and -30 euros. Since the CRIPS measure is additive, it can be used to measure credit risk volume (in euros) of a bond portfolio.

Thirdly the TSDPs of the Four States were derived via CB-pricing model in Kariya (2013) and compared. The model enabled us to transform the term structures of CRiPSs into TSDPs, and it turned out that the 10-year CRiPSs of Italy and Spain in 2011.12 respectively corresponded to about 35 and $30 \%$ where the recovery rate was assumed to be zero. In addition we substantiated the observations on the credit differentiation obtained through our TSIR analysis in terms of the DPs. Also it was observed that the Financial Crisis did not affect the DPs of France, did increase the DPs of Italy, Spain and Greece to the levels of 6,10 and 20\% respectively, but after that their DPs decreased. The time series movements of the TSDPs of the Four States were associated with business cycles, Financial Crisis and Euro Crisis.

Fourthly the time series relationships between the IR-differentials and the DPs of each maturity were shown to be strongly linear by our regression analysis, which enables us to convert the IR-differentials into the DPs for each maturity and vice versa. Consequently the Maastricht convergence condition can be stated in terms of the DPs. It was observed that Italy, Spain and Greece did not meet the required condition in the period of the Euro Crisis though they are the members of the EEMU, creating the instability of the EEMU system that was an economic concern in the global world. But an explicit solution that President Van Rompuy (2012) planned for a genuine integration of the EEMU will stabilize the EEMU.

Finally we made compared the CDS prices of each maturity to our TSDPs by term series regression and found that the CDS prices were well explained by the DP levels and the slopes of TSDPs. Since the CDS prices are formed in a different market by different players, this result will show that our approach and model to deriving the TSDPs are effective. In addition the regression model will enable us to use for trading CDSs.

Overall, our empirical model analysis on credit risks of the main states of the EEMU will be effective and the results therein will be useful for decision making in credit investment and risk management.

Acknowledgments This research was supported by the Japan Society for the Promotion of Science (JSPS), Grant-in-Aid for Scientific Research (A),No.23243040. 
Open Access This article is distributed under the terms of the Creative Commons Attribution License which permits any use, distribution, and reproduction in any medium, provided the original author(s) and the source are credited.

\section{Appendix A}

A. Covariance structure of $k \mathrm{~GB}$ prices in (5.2) with $\mathrm{CFs}$ in (5.3). Assuming the covariance structure in (3.5) for the stochastic discount function yields

$$
\begin{aligned}
\operatorname{Cov}\left(\varepsilon_{g}^{k}, \varepsilon_{h}^{k}\right) & =\sum_{j=1}^{M^{k}(g)} \sum_{m=1}^{M^{k}(h)} \bar{C}_{g}^{k}\left(s_{g j}^{k}: \beta^{k}\right) \bar{C}_{h}^{k}\left(s_{h m}^{k}: \beta^{k}\right) \operatorname{Cov}\left(\Delta_{g j}^{k}, \Delta_{h m}^{k}\right) \\
& =\left(\sigma^{k}\right)^{2} \lambda_{g h}^{k} \varphi_{g h}^{k},
\end{aligned}
$$

where $\lambda_{g h}^{k}$ is the same as the one in (3.5) and similarly to (3.7)

$$
\varphi_{g h}^{k}=\sum_{j=1}^{M^{k}(g)} \sum_{m=1}^{M^{k}(h)} \bar{C}_{g}^{k}\left(s_{g j}^{k}: \beta^{k}\right) \bar{C}_{h}^{k}\left(s_{h m}^{k}: \beta^{k}\right) .
$$

However a significant difference is that this covariance matrix depends on the unknown regression parameters $\beta^{k}$ to be estimated. Of course our objective function to be minimized is of the same form as (3.10);

$$
\psi\left(\beta^{k}, \rho^{k}, \xi^{k}\right)=\left[y^{k}-X^{k} \beta^{k}\right]^{\prime}\left[\Phi\left(\beta^{k}, \rho^{k}, \xi^{k}\right)\right]^{-1}\left[y^{k}-X^{k} \beta^{k}\right]
$$

where the covariance matrix is replaced by the matrix $\left(\left(\sigma^{k}\right)^{2} \lambda_{g h}^{k} \varphi_{g h}^{k}\right)$ in (8.1). To get an approximate minimize, the GLS is applied in a repeated manner. In fact, we set $\beta^{k}=0$ as the initial value in the covariance matrix (8.1) to obtain the first GLS estimate $\hat{\beta}^{k}(1)$ by minimizing (8.3). Next we insert $\hat{\beta}^{k}(1)$ into (8.1) and get the second GLS estimate $\hat{\beta}^{k}(2)$. Repeating this procedure five times yields our GLS estimate the coefficients $\hat{\beta}^{k}(5)$ of the TSDP in (5.4). The minimized value is $\hat{\psi}^{k}=\hat{\psi}\left(\hat{\beta}^{k}(5), \hat{\rho}^{k}, \hat{\xi}^{k}\right)$.

\section{References}

Diebold, F. X., \& Li, C. (2006). Forecasting the term structure of government bond yields. Journal of Econometrics, 130, 337-364.

Duan, J. C., Sun, J., \& Wang, T. (2011). Multiperiod corporate default prediction-a forward intensity approach, RMI working paper No.10/07, National University of Singapore.

Duffie, D. (2011). Measuring corporate default risk. Clarendon lectures in finance. Oxford: Oxford University Press.

Duffie, D., Eckner, A., Horel, G., \& Saita, I. (2009). Frailty correlated default. Journal of Finance, 64, 2089-2123.

Duffie, D., Saita, I., \& Wang, K. (2007). Multi-period corporate default prediction with stochastic covariates. Journal of Financial Economics, 83, 635-665. 
Duffie, D., \& Singleton, K. J. (2003). Credit risk pricing, measurement, and management. Princeton: Princeton University Press.

Friewald, N., Jankowitsch, R., \& Subrahmanyam, M. G. (2012). Illiquidity or credit deterioration: A study of liquidity in the US corporate bond market during financial crises. Journal of Financial Economics, $105,18-36$

Kariya, T. (1993). Quantitative methods for portfolio analysis: MTV approach. Berlin: Springer.

Kariya, T. (2013). A CB (corporate bond) pricing model for deriving default probabilities and recovery rates. In Garlin, J., \& Xiaotong, S. (Eds.), Advances in modern statistical theory and applications: A Festschrift for Professor Morris L. Eaton (pp. 136-155). Beachwood: Institute of Mathematical Statistics.

Kariya, T., \& Kurata, H. (2004). Generalized least squares. New York: Wiley.

Kariya, T., Wang, J., Wang, Z., Doi, E., \& Yamamura, Y. (KWWDY) (2012). Empirically effective bond pricing model and analysis on term structures of implied interest rates in financial crisis. Asia-Pacific Financial Markets, 19, 259-292.

Lando, D. (2004). Credit risk modeling. Princeton: Princeton University Press.

Maastricht Treaty and Euro Convergence Criteria, Wikipedia.

Nelson, C. R., \& Siegel, A. F. (1987). Parsimonious modeling of yield curves. Journal of Business, 60(4), 473-489.

Treaty of Maastricht on European Union. http://europa.eu/legislation_summaries/institutional_affairs/ treaties/treaties_maastricht_en.htm.

Van Rompuy, H. (2012). Toward a genuine economic and monetary union. European Commission. 